University of Nebraska - Lincoln

DigitalCommons@University of Nebraska - Lincoln

USDA Forest Service / UNL Faculty Publications U.S. Department of Agriculture: Forest Service -National Agroforestry Center

2011

Evaluation of the MODIS LAI product using independent lidarderived LAl: A case study in mixed conifer forest

Jennifer L.R. Jensen

Texas State University, jj41@txstate.edu

Karen S. Humes

University of Idaho, khumes@uidaho.edu

Andrew T. Hudak

Rocky Mountain Research Station, ahudak@fs.fed.us

Lee A. Vierling

University of Idaho, leev@uidaho.edu

Eric Delmelle

University of North Carolina at Charlotte, eric.delmelle@uncc.edu

Follow this and additional works at: https://digitalcommons.unl.edu/usdafsfacpub

Part of the Forest Biology Commons, Forest Management Commons, Other Forestry and Forest Sciences Commons, and the Plant Sciences Commons

Jensen, Jennifer L.R.; Humes, Karen S.; Hudak, Andrew T.; Vierling, Lee A.; and Delmelle, Eric, "Evaluation of the MODIS LAI product using independent lidar-derived LAI: A case study in mixed conifer forest" (2011). USDA Forest Service / UNL Faculty Publications. 214.

https://digitalcommons.unl.edu/usdafsfacpub/214

This Article is brought to you for free and open access by the U.S. Department of Agriculture: Forest Service -National Agroforestry Center at DigitalCommons@University of Nebraska - Lincoln. It has been accepted for inclusion in USDA Forest Service / UNL Faculty Publications by an authorized administrator of DigitalCommons@University of Nebraska - Lincoln. 


\title{
Evaluation of the MODIS LAI product using independent lidar-derived LAI: A case study in mixed conifer forest
}

\author{
Jennifer L.R. Jensen ${ }^{\text {a,* }}$, Karen S. Humes ${ }^{\text {b }}$, Andrew T. Hudak ${ }^{c}$, Lee A. Vierling ${ }^{d}$, Eric Delmelle ${ }^{\mathrm{e}}$ \\ a Department of Geography, Texas Center for Geographic Information Science, 601 University Drive, Texas State University, San Marcos, San Marcos, TX 78666, United States \\ b Department of Geography, McClure Hall 203, P.O. Box 443021, University of Idaho, Moscow, ID 83844, United States \\ ${ }^{c}$ Rocky Mountain Research Station, US Department of Agriculture Forest Service, 1221 South Main Street, Moscow, ID 83843, United States \\ d Department of Rangeland Ecology and Management, Geospatial Laboratory for Environmental Dynamics, College of Natural Resources, Room 205E, University of Idaho, Moscow, \\ ID 83844, United States \\ e Department of Geography and Earth Sciences and Center for Applied Geographic Information Science, University of North Carolina at Charlotte, Charlotte, NC 28223, United States
}

\section{A R T I C L E I N F O}

\section{Article history:}

Received 6 November 2010

Received in revised form 22 August 2011

Accepted 27 August 2011

Available online 25 September 2011

\section{Keywords:}

Leaf area index

LAI

Lidar

MODIS

Sub-pixel

Vegetation structure

Conifer

Evergreen needleleaf

\begin{abstract}
A B S T R A C T
This study presents an alternative assessment of the MODIS LAI product for a 58,000 ha evergreen needleleaf forest located in the western Rocky Mountain range in northern Idaho by using lidar data to model $\left(R^{2}=0.86\right.$, RMSE $=0.76$ ) and map LAI at higher resolution across a large number of MODIS pixels in their entirety. Moderate resolution $(30 \mathrm{~m}$ ) lidar-based LAI estimates were aggregated to the resolution of the $1-\mathrm{km}$ MODIS LAI product and compared to temporally-coincident MODIS retrievals. Differences in the MODIS and lidar-derived values of LAI were grouped and analyzed by several different factors, including MODIS retrieval algorithm, sun/sensor geometry, and sub-pixel heterogeneity in both vegetation and terrain characteristics. Of particular interest is the disparity in the results when MODIS LAI was analyzed according to algorithm retrieval class. We observed relatively good agreement between lidar-derived and MODIS LAI values for pixels retrieved with the main RT algorithm without saturation for LAI $\mathrm{LAI} \leq 4$. Moreover, for the entire range of LAI values, considerable overestimation of LAI (relative to lidar-derived LAI) occurred when either the main RT with saturation or back-up algorithm retrievals were used to populate the composite product regardless of sub-pixel vegetation structural complexity or sun/sensor geometry. These results are significant because algorithm retrievals based on the main radiative transfer algorithm with or without saturation are characterized as suitable for validation and subsequent ecosystem modeling, yet the magnitude of difference appears to be specific to retrieval quality class and vegetation structural characteristics.
\end{abstract}

(c) 2011 Elsevier Inc. All rights reserved.

\section{Introduction}

Quantifying and monitoring productivity of terrestrial landscapes relies on the ability to account for specific canopy structural characteristics such as leaf area index (LAI), the ratio of green foliage area per unit ground area. The foliage of vegetation canopies serves as the primary surface for mass and energy exchange between the atmosphere and terrestrial surface (Sellers et al., 1997), thus LAI is often utilized as a primary input or validation measure for spatially-explicit models of vegetation productivity, hydrologic forecasting, evapotranspiration, and surface energy balance (Bonan, 1993; Running \& Coughlan, 1988; Turner et al., 2004).

\footnotetext{
* Corresponding author. Tel.: +1 5122451724 .

E-mail addresses: jjensen@txstate.edu (J.L.R. Jensen), khumes@uidaho.edu (K.S. Humes), ahudak@fs.fed.us (A.T. Hudak), leev@uidaho.edu (L.A. Vierling), Eric.Delmelle@uncc.edu (E. Delmelle).
}

Local and regional estimates of LAI traditionally have been determined by establishing relationships between multispectral band information from high resolution passive optical sensors and field-measured LAI obtained from destructive sampling or optical instruments (Berterretche et al., 2005; Chen \& Chilar, 1996; Curran, 1983; Curran \& Williamson, 1987; Fernandez et al., 2004; Jordan, 1969; White et al., 1997). Moreover, this method of localized LAI estimation has been the most frequently employed method to evaluate the performance and accuracy of coarse resolution operational LAI products. While multispectral-based methods may be appropriate for many vegetation types and biomes with relatively low LAI (e.g. LAI $\leq 3-5$ ) (Chen \& Chilar, 1996; Turner et al., 1999), LAI estimation for canopies above this LAI threshold remains a significant challenge. In light of this problem, recent studies suggest lidar as a compelling means to estimate LAI in moderate to high biomass ecosystems using either airborne (Chen et al., 2004; Jensen et al., 2008; Morsdorf et al., 2006; Riaño et al., 2004; Zhao \& Popescu, 2009) or terrestrial-based (Clawges et al., 2007) lidar systems. 
Moderate Resolution Imagining Spectroradiometer (MODIS) data are currently used to derive a $1 \mathrm{~km}$ (actual pixel dimension of $926.625 \mathrm{~m}$ ) LAI product at 4- and 8-day product intervals based on the observed maximum fraction of photosynthetically-active radiation (fPAR) (Knyazikhin et al., 1999). Significant efforts have been invested

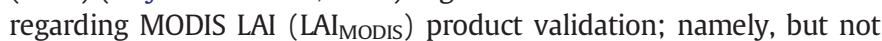
limited to, investigations via the BigFoot project (Cohen et al., 2003; Cohen \& Justice, 1999) and $\mathrm{LAI}_{\text {MODIS }}$ algorithm development and validation activities (e.g. Myneni et al., 2002; Tian et al., 2002; Yang et al., 2006a,b,c). A suite of published works have assessed the agreement between MODIS-derived LAI via radiative transfer inversion compared to multispectral-based empirical estimates of LAI for a variety of vegetation biome types including evergreen needleleaf forests (Chen et al., 2005; Cohen et al., 2006, 2003; De Kauwe et al., 2011; Heinsch et al., 2006; Pisek \& Chen, 2007; Wang et al., 2004), broadleaf crops (Tan et al., 2005), evergreen deciduous (Aragão et al., 2005), and semi-arid landscapes (Cohen et al., 2006; Fensholt et al., 2004; Hill et al., 2006; Pisek \& Chen, 2007).

Prior MODIS product assessments have identified study-specific retrieval conditions that influence $\mathrm{LAI}_{\mathrm{MODIS}}$ retrieval accuracy including aerosol contamination (Yang et al., 2006b), input surface reflectance (Tan et al., 2005; Wang et al., 2001; Yi et al., 2008), sensor view zenith angle (Tan et al., 2005) and land cover classification (Cohen et al., 2003; Heinsch et al., 2006; Myneni et al., 2002). Such studies are valuable as they provide insight regarding algorithm performance and contribute information that may be used for algorithm improvement and refinement.

Part of the difficulty in determining specific causes of LAI $\mathrm{MODIS}_{\mathrm{S}}$ retrieval accuracy was expressed by Tan et al. (2005), who summarized that variation in retrieval method complicates any inferences made regarding the true error associated with a specific pixel because $\mathrm{LAI}_{\text {MODIS }}$ may vary significantly over a short period of time. The cause of such variation is largely attributed to the aforementioned upstream data products and input data quality (Yang et al., 2006a). Though these prior assessments are undoubtedly of great value, it is reasonable to consider that multispectral evaluation products may be subject to similar conditions and constraints as the $\mathrm{LAI}_{\mathrm{MODIs}}$ products, and hence any inferences drawn.

In terms of lidar-based MODIS product evaluation, Chasmer et al. (2008) examined the agreement between lidar-modeled and MODIS-retrieved PPAR and found that lidar-based canopy fPAR estimates were within $10 \%$ of MODIS retrievals. To our knowledge, a lidar-based $\mathrm{LAI}_{\text {MODIs }}$ product evaluation has not been addressed. Given that lidar data are not prone to the same saturation issues as passive multispectral sensors, lidar data can be used to discriminate higher values of LAI, which makes it valuable for comparison with coarse-resolution LAI products in moderate-to-high biomass ecosystems or for vegetated landscapes where modeling of canopy LAI is influenced by understory vegetation reflectance.

Importantly, active lidar sensors respond more directly to the structural characteristics of the canopy than passive optical sensors, and LAI is fundamentally a structural characteristic. Further, previous studies of LAI in northern Idaho conifer forests have reported LAI ranging from 0 to 13 , with the majority of observations exceeding LAI = 4 (Duursma et al., 2003; Jensen et al., 2008; Pocewicz et al., 2004). As a result, LAI estimates based on lidar data should be more accurate and consistent across variable atmospheric and solar illumination conditions than LAI estimates based on multispectral remote sensing data (e.g. Landsat or SPOT) for the purpose of MODIS-retrieved LAI product comparisons, and thus may reveal insights to improving or characterizing conditions that influence LAI retrieval accuracy or quality. As such, our primary research objectives were to: 1 ) evaluate the agreement between

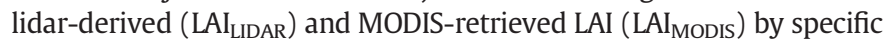
MODIS algorithm retrieval class, and 2) evaluate the conditions over which LAI MODIS retrievals may be influenced by sun/sensor view angles or sub-pixel structural characteristics.

\section{Materials and methods}

\subsection{Study area}

The St. Joe Woodlands (SJW) study area is located along the western edge of the Rocky Mountains in northern Idaho, USA. (N47 $07-N 47^{\circ} 17^{\prime}$ and $\mathrm{W} 115^{\circ} 58^{\prime}-\mathrm{W} 116^{\circ} 22^{\prime}$ ) The area totals approximately 58,000 ha. The SJW is an evergreen needleleaf forest landscape dominated by Thuja plicata (THPL; western red cedar) and Abies grandis (ABGR; grand fir), though other important conifer species including Pseudotsuga menziesii (PSME, Douglas fir), Larix occidentalis (LAOC; western larch), Tsuga heterophylla (TSHE, western hemlock), Abies lasiocarpa (ABLA; subalpine fir), Picea engelmannii (PIEN; Engelmann spruce), Pinus contorta (PICO; lodgepole pine), Pinus ponderosa (PIPO; ponderosa pine), and Pinus monticola (PIMO; western white pine) occur in mixed stands throughout the study area (Hudak et al., 2006). Understory vegetation is comprised of perennial herbs, shrubs and ferns including snowberry (Symphoricarpos spp), huckleberry (Vaccinium globulare Rydb), thimbleberry (Rubus parviflorus Nutt), twinflower (Linnaea spp), Kunth bride's bonnet (Clintonia unifora), American trailplant (Adenocaulon bicolor Hook), common ladyfern (Anthyrium filix-femina) and alder (Alnus spp).

Elevation ranges from 658 to $2000 \mathrm{~m}$ with most of the study area exhibiting complex terrain (e.g. slopes range from 0 to $51^{\circ} ; \mu=17^{\circ}$ ). Mean annual temperature and total annual precipitation are $8.5^{\circ} \mathrm{C}$ and $124.4 \mathrm{~cm}$, respectively. The area is managed for commercial timber production where primary harvest activities include selective thinning and clear-cut operations. As such, rotations of large tracts of forest land are common, the result being a matrix of evergreen needleleaf forest in various seral stages.

\subsection{LAI field data collection and processing}

Field data were acquired for forty-six 0.07 ha ( $15 \mathrm{~m}$ radius) forest inventory plots during the summer and early Fall of 2006 (Julian Dates (JD) 264-266; 287) and 2007 (JD 200-204; 255-258; 249). In 2003, Hudak et al. (2006) established and inventoried forest plots in the SJW for a lidar-multispectral integration study to estimate conifer basal area and stem density. Of the 81 original plots established by Hudak et al. (2006), a subset of plots $(n=46)$ was selected for LAI measurements relevant to this study. During the plot selection process for this study we excluded very young regeneration stands since such stands tend to be dominated by shrubs and would exhibit higher growth rates than mid-to-late seral and mature stands. We also excluded plots that had been disturbed by forest management activities during the intervening three years. Selection of the final 46 plots was based on a stratified random approach that best represented the diversity of species, size, and stem density in proportion to their occurrence. Such plot selection restrictions were implemented to mitigate temporal differences in field observations and lidar acquisitions discussed in the next section.

Field observations of effective LAI were acquired using two LAI-2000 Plant Canopy Analyzers. The LAI-2000 implements a fisheye optical sensor comprised of five concentric silicon detector rings for a $148^{\circ}$ field of view to simultaneously measure attenuation of diffuse solar radiation transmitted through a vegetation canopy (Welles \& Norman, 1991). The first sensor was mounted and leveled on a tripod in a nearby clearing and programmed to automatically log readings of sky condition at $15 \mathrm{~s}$ intervals, while the second sensor was used to rove within forest plots for manual collection of temporally-coincident below-canopy readings. Both sensors were affixed with 45-degree view restrictors to mitigate limitations imposed by lack of substantial clearings (for above-canopy readings) and to minimize slope effects. Three below-canopy measurements were obtained $1 \mathrm{~m}$ on either side of six LAI sample stations at a height of $1.37 \mathrm{~m}$ resulting in a total of 36 canopy vegetation observations for each plot (Fig. 1). 


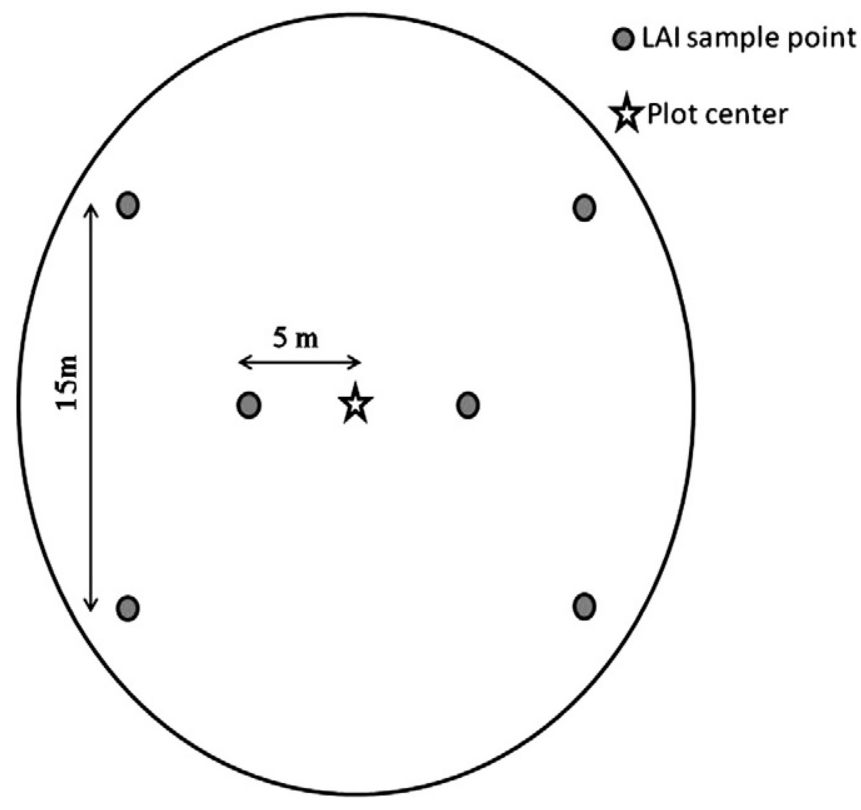

Fig. 1. LAI sampling design within a $15 \mathrm{~m}$-radius sample plot. Six LAI-2000 measurements were collected at individual LAI sample points within each plot for a total of 36 LAI measurements per plot.

Raw LAI-2000 data were post-processed to calculate effective LAI using the vendor-provided FV-2000 software. The first and fifth rings were excluded from LAI calculation due to the sensitivity of Ring 1 to sensor position with respect to crown projection (Law et al., 2001) and additional contribution of diffuse light in Ring 5 from multiple scattering (Chen et al., 1997). Effective LAI (also referred to as Plant Area Index, or PAI) is the suggested term for values calculated directly from gap fraction information (Chen \& Black, 1991; Oker-Blom \& Smolander, 1988; Smith et al., 1993) by optical instruments such as the LAI-2000 Plant Canopy Analyzer, AccuPAR ceptometer, or hemispherical canopy photography. In needleleaf forests, true conifer LAI can be obtained by correcting effective LAI for both shoot- and canopy gap-level clumping and by subtracting the contribution from woody materials (Chen \& Chilar, 1995). The boxplots provided in Fig. 2 characterize the distribution of mean and maximum measured effective LAI within dominant species classes to demonstrate the range of values measured in our sample plots.

\subsection{Lidar data processing and LAI modeling}

Lidar data were acquired during summer 2003 (JD 204, 224) with a Leica ALS40 lidar sensor according to the detailed acquisition parameters described in Table 1 . Raw lidar data containing $\mathrm{x}, \mathrm{y}, \mathrm{z}$ coordinates for each return were processed with the multi-scale curvature classification (MCC) algorithm (Evans \& Hudak, 2007) to classify ground vs. non-ground returns. Ground returns were used to generate a $1 \mathrm{~m}$ digital terrain model (DTM) of the ground surface to account for topographic variation in the point cloud. The DTM was subtracted from the raw lidar returns to determine canopy heights associated with non-ground lidar returns.

A suite of metrics calculated from the lidar-derived canopy heights (see Jensen et al., 2008) was used as predictor variables in a multiple linear regression framework to estimate field-measured effective LAI. The best-subset regression procedure, PROC REG, available in the statistical analysis software (SAS) package (SAS Institute, Cary, N.C.) was used to identify suitable models. Potential models were initially narrowed based on strict criteria imposed to prevent model overfit from inclusion of excessive or redundant covariate terms. Candidate models were evaluated based on $\mathrm{R}^{2}$, adjusted $\mathrm{R}^{2}$, root mean square error (RMSE), AIC (Suguira, 1978), individual covariate significance
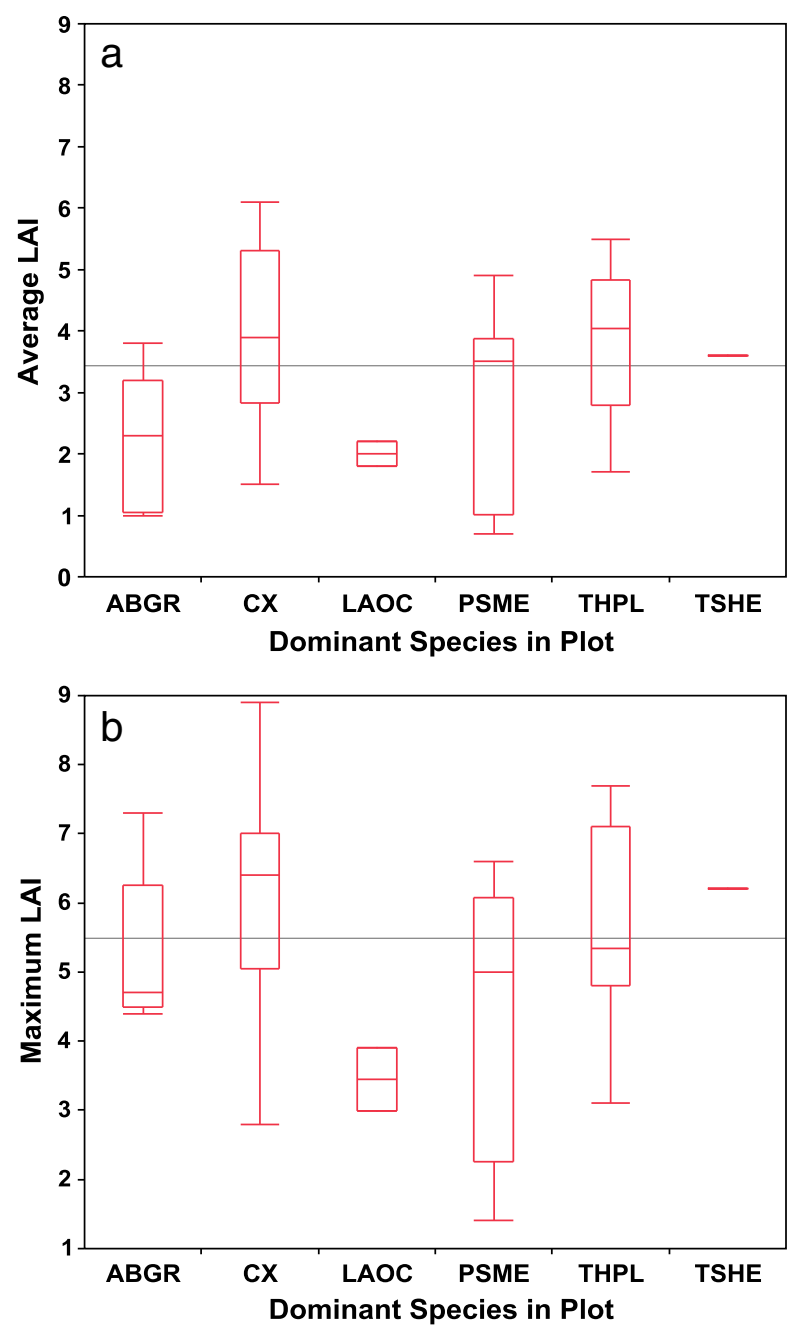

Fig. 2. Distributions for plot-level mean (a) and maximum (b) field-measured effective LAI grouped by dominant species. ABGR - Abies grandis $(n=5) ; C X-$ mixed conifer $(\mathrm{n}=20)$; LAOC - Larix occidentalis $(\mathrm{n}=2)$; PSME - Pseudotsuga menziesii $(\mathrm{n}=8)$; THPL - Thuja plicata $(\mathrm{n}=10)$; TSHE - Tsuga heterophylla $(\mathrm{n}=1)$.

(Type III error $t$ tests, $\alpha=0.05$ ), absence of multicollinearity (i.e. tolerance $>0.1$, Neter et al., 1985), and residual homoscedasticity. Subsequent model selection was based on candidate model performance using the Predicted Residual Sum of Squares (PRESS) statistic (Allen, 1974), a leave-one-out cross validation technique. Final model selection was based on a combination of lowest AICc, smallest changes in $\mathrm{R}^{2}$ to adjusted $\mathrm{R}^{2}$, and the lowest full-dataset RMSE to PRESS RMSE ratio.

Table 1

Lidar acquisition parameters.

\begin{tabular}{ll}
\hline Acquisition parameter & Value \\
\hline Date acquired & 23-Jul-2003 \\
& 23 -Aug-2003 \\
Sensor & Leica ALS40 \\
Wavelength $(\mathrm{nm})$ & 1064 \\
Flight height $(\mathrm{m})^{\mathrm{a}}$ & 2438 \\
Footprint diameter $(\mathrm{cm})$ & 30 \\
Post-spacing $(\mathrm{m})$ & 1.95 \\
Scan/pulse rates $(\mathrm{Hz} / \mathrm{kHz})$ & $17.1 / 20.0$ \\
Scan angle $\left(^{\circ}\right)$ & $+/-20^{\mathrm{b}}$ \\
Average swath width $(\mathrm{m})$ & 904 \\
Average point density $\left(\mathrm{m}^{2}\right)$ & 0.26 \\
\hline
\end{tabular}

a Above mean terrain.

b Scan angles $>15^{\circ}$ were discarded (after Hudak et al., 2006). 


\subsection{Lidar mapped estimates of LAI}

To map lidar-modeled effective LAI, a $30 \mathrm{~m}$ grid was generated for the study area extent and overlain on the point-based lidar-calculated vegetation heights. Layers corresponding to the lidar covariates of the selected model were calculated for each grid cell. The resulting four layers were used to calculate a per-pixel effective LAI value for each $30 \mathrm{~m}$ grid cell. Since the model consisted of log-transformed fieldmeasured LAI, a bias correction for back-transformation (Baskerville, 1972 ) was also applied to each output pixel $\left(\mathrm{LAI}=\mathrm{y}_{\mathrm{pred}} e^{0.5 * \mathrm{MSE}}\right)$ to yield the final lidar-based LAI map. The fine resolution lidar LAI map was re-projected from the native UTM Zone 11N NAD83 to the MODIS Sinusoidal projection as recommended by Morisette et al. (2006).

\subsection{MODIS LAI product information and data processing}

The LAI $_{\text {MODIs }}$ product is derived under optimal conditions by employing a three-dimensional canopy radiative transfer (RT) model (Myneni et al., 2002). The RT model is used by the main LAI algorithm to derive a relationship between canopy structural characteristics and observed vegetation canopy spectral reflectance values, which are then used to relate LAI to measured spectral reflectances stored in a look-up-table (Knyazikhin et al., 1998; Myneni et al., 1997). When the main LAI algorithm fails to find an acceptable solution to the inversion problem, a back-up algorithm is used to retrieve LAI based on observed relationships between LAI and the Normalized Difference Vegetation Index (NDVI) (Myneni et al., 1997).

The $\mathrm{LAI}_{\text {MODIs }}$ spatial data set also includes pixel-specific quality information pertaining to the specific method of LAI retrieval. This information is stored within 8-bitwords. The first two bitwords specify if the main (RT inversion) or backup (NDVI) algorithm was employed for retrieval. More specific information regarding exact retrieval method is stored in bitwords 5-7. For instance, inversion of the RT model results in multiple solutions. As such, LAI retrieved via the RT inversion algorithm is separated into two retrieval classes. When the distribution of possible solutions exhibits low variance, the

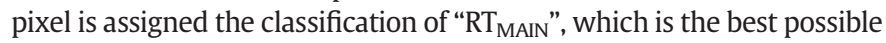
result as specified in the dataset documentation. However, when the distribution exhibits a "wide" set of possible solutions, the retrieval is considered saturated. In such cases, the retrieved LAI value is a statistical average of high variance solutions (Knyazikhin et al., 1999). In this paper, we refer to such pixel retrievals as " $\mathrm{RT}_{\mathrm{SAT}}$ ". The remaining descriptions of algorithm retrieval method classifications describe whether the main algorithm was not used due to geometry problems $\left(\mathrm{EMP}_{\mathrm{GEO}}\right)$, problems other than geometry, such as failure of inputs to meet minimum quality thresholds $\left(\mathrm{EMP}_{\mathrm{NDVI}}\right)$, or if the pixel was not produced at all. Our study area exhibited four of five possible retrieval classes over the course of $2003\left(\mathrm{RT}_{\mathrm{MAIN}}, \mathrm{RT}_{\mathrm{SAT}}, \mathrm{EMP}_{\mathrm{GEO}}\right.$, and EMP $\left.\mathrm{NDVI}_{\mathrm{NDI}}\right)$.

MODIS Terra 8-day composited LAI (MOD15A2) was downloaded from the LDAAC database (http://edcimswww.cr.usgs.gov/pub/ imswelcome/) for 2003 to correspond to the year of lidar acquisition. LAI data were scaled by 0.1 to produce LAI in $\mathrm{m}^{2} / \mathrm{m}^{2}$ and bitwords $5-7$ were extracted from each composite dataset to determine the specific retrieval method (class) for each pixel in the 8-day composites.

\subsection{Daily MODIS LAI and sun/sensor angles}

MODIS daily LAI datasets (MOD15A1) were requested and delivered by the MODIS Data Processing System (MODAPS) and span the time period coincident to five 8-day composites (i.e. JD 201-240; 40 days) closest in time to the lidar acquisition dates (JD 204 and JD 224, 2003). The MOD15A1 data were used to determine which daily LAI value was used solely to populate the pixels for each 8-day composite product. From this information, we joined coincident solar
(SOLZ) and sensor (SENZ) zenith angle and sensor azimuth (SENA) angles information provided by the MODIS Level 1A Earth Location product to the MODIS retrieved pixels that populated each composite product.

\subsection{Lidar-based measures of within-pixel structural characteristics}

Vegetation structural complexity was characterized by quantifying the heterogeneity of moderate resolution (i.e. 30 m lidar-mapped) LAI estimates and lidar-derived mean height within each $1 \mathrm{~km}$ MODIS pixel. To represent both topographic and vegetation structural complexity, the coefficient of variation (CV) for the VRM $\left(\mathrm{VRM}_{\mathrm{CV}}\right)$, $30 \mathrm{~m}$ lidar-modeled LAI (LAI LIDAR CV) and mean $30 \mathrm{~m}$ lidar height (Height $_{\text {LIDAR }}$ CV) were calculated for each $1 \mathrm{~km}$ pixel. CV is a unitless value that describes a normalized measure of dispersion; where low $\mathrm{CV}$ values (e.g. close to zero) indicate low structural complexity (i.e. values are relatively homogeneous within $1 \mathrm{~km}$ pixel) and high CV values (i.e. $\geq 1$ ) indicate heterogeneous conditions within each $1 \mathrm{~km}$ pixel.

Landscape structural complexity encompasses both topographic variation and vegetation distribution and structure. Topography can influence the distribution and density of species, and subsequently LAI, due to variations in temperature, moisture, and solar radiation (Bolstad et al., 2001). Additionally, highly variable terrain results in increased angular variation between insolation and reflected energy which may introduce further complexity with respect to bidirectional reflectance distribution (Pocewicz et al., 2004). As such, we hypothesized that within-pixel topographic complexity, quantified by the Vector Ruggedness Measure (VRM); (Sappington et al., 2005) would influence MODIS retrieval quality. To quantify topographic complexity, we employed the lidar-derived terrain model to calculate the VRM and used the coefficient of variation of VRM (VRM CV) to characterize within-pixel terrain complexity for each $1 \mathrm{~km}$ MODIS pixel. The VRM characterizes terrain ruggedness by measuring the dispersion of normal vectors relative to the terrain surface. Sappington et al. (2005) found VRM to be uncorrelated with slope, thus providing an independent measure of terrain complexity that incorporates variability in both aspect and slope gradient.

\section{8. $L A I_{M O D I S}$ and LAI LIDAR Comparisons}

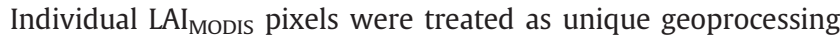
elements and overlain on the fine resolution $30 \mathrm{~m}$ lidar-modeled LAI. Spatially-coincident LAI LIDAR was derived by calculating the mean of all $30 \mathrm{~m}$ lidar LAI pixels within each MODIS pixel. This process was repeated for the five 8-day MODIS composite periods. $\mathrm{LAI}_{\Delta}$ $\left(\mathrm{LAI}_{\mathrm{MODIS}}-\mathrm{LAI}_{\text {LIDAR }}\right)$ values were characterized for the entire study area (i.e. study area mean; $5561 \mathrm{~km}^{2}$ pixels) and on a per-pixel basis by algorithm retrieval class. Study area mean values were tested for statistically significant differences in means using Tukey's Honestly Significant Difference (HSD) tests to determine if JD composite means differed from each other or the aggregated lidar-modeled LAI ( LAI $_{\text {LIDAR }}$ ) values. Tukey's HSD test is conducted on a pair-wise basis, where the mean from each composite period was compared to every other dataset mean. This method of means comparison is preferable to independent t-tests because Tukey's HSD corrects for experiment-wise error rate. Standard deviation values of the MODIS pixel retrievals or standard errors of the lidar-based model were not incorporated due to the lack of consistency of same-pixel retrieval algorithm.

Though annual $\mathrm{LAI}_{\mathrm{MODIS}}$ for 2003 was obtained, interpretation of $\mathrm{LAI}_{\Delta}$ was limited to the retrieval dates (JD composites 201-233; July 20 -August 28, 2003) that directly preceded, were concurrent with, or immediately followed the lidar and field data acquisitions with respect to time of year. Relationships among $\mathrm{LAI}_{\Delta}$, MODIS sun/sensor angles, and sub-pixel vegetation and landscape complexity were 
evaluated by summarizing each factor by the specific algorithm retrieval class (e.g. $\mathrm{RT}_{\mathrm{MAIN}}, \mathrm{RT}_{\mathrm{SAT}}$, etc.) and presenting the results graphically.

\subsection{Physical differences in LAI and implications for analysis}

Significant improvements to Collection 5 include implementation of a new stochastic radiative transfer model, improved characterization of the three-dimensional radiation regime, and recalibration of the Look-up-Tables used to find solutions to the inverse problem. These enhancements ultimately provide a better representation of the three-dimensional effects of vegetation heterogeneity, and thus offer an improved characterization foliage clumping effects (i.e., shoot- and crown-level clumping) and species heterogeneity (Huang et al., 2008). In light of these improvements to the main RT algorithm, LAI $_{\text {MODIS }}$ is considered a true LAI product (i.e., foliage clumping is accounted for but contribution from woody materials is considered minimal and therefore ignored).

The differences in LAI products in this case study have specific implications in regard to our comparisons. First, LAI LIDAR must be viewed as an underestimate of true conifer LAI since we measured effective LAI, which was calculated directly from plot-level gap fraction information obtained by the LAI-2000 instruments. Second, the results of our analysis should not be interpreted as a validation/invalidation of the LAI ${ }_{\text {MODIs }}$ product, but rather a comparison of lidar-derived LAI and the vegetation and landscape structural conditions over which $\mathrm{LAI}_{\text {MODIS }}$ varies in agreement with $\mathrm{LAI}_{\mathrm{LIDAR}}$.

\section{Results}

\subsection{Lidar-based LAI model results and $30 \mathrm{~m}$ mapped estimates}

Lidar-derived model covariates explained a substantial amount of variation $\left(R^{2}=0.86, \quad R M S E=0.76 \mathrm{~m}^{2} / \mathrm{m}^{2}\right)$ in field-measured LAI. Based on the criteria described in the methodology section, a four-covariate model to estimate field-measured effective LAI $\left(R^{2}=0.86\right.$, RMSE $\left.=0.76, p \leq 0.0001\right)$ was selected for subsequent LAI mapping of the entire study area (Fig. 3). Lidar covariates used to estimate log-transformed LAI included kurtosis and maximum height of all lidar returns per plot as well as the 25th percentile of upperstory $(>1.37 \mathrm{~m})$ heights and the difference between the upperstory 95th percentile and the 25th percentile height. Lidar-modeled LAI exhibited slight estimation errors with an average absolute residual error of 0.56 LAI. Large residual errors (LAI residual $>1$ ) occurred in six plots; these plots were classified as mixed conifer (CX) stands with large proportions (e.g. $\geq 50 \%$ and $<80 \%$ total basal area) of Western Red Cedar, Grand Fir, or Douglas fir.

\subsection{Comparison of study area mean $L A I_{M O D I S}$ and $L A I_{L I D A R}$}

An overview of the mean LAI $_{\text {MODIs }}$ value by 8-day composite period for the study area is provided in Fig. 5 . The annual pattern of LAI $_{\text {MODIS }}$ is shown here for context; this analysis only quantitatively compares LAI $_{\text {MODIS }}$ values acquired at the same time of year as the lidar data (i.e., time of peak greenness). LAI ModIs values exhibit strong seasonality over the course of the year, ranging from 0 to 2.6 in winter, 0.5 to 3.3 in spring, 3.3 to 4.5 in summer, and 0 to 2.7 in the fall. Winter-low seasonal LAI trends over northern temperate and boreal forest ecosystems has been an oft-cited concern among studies over similar ecosystem types for multiple MODIS collections (Chen et al., 2005; Tian et al., 2004) and is largely attributed to snow effects on surface reflectance.

Summarized in Table 2 are the average LAI values for the entire study area for MODIS composite periods JD 201, 209, 217, 225, and 233. The datasets used for analysis include all algorithm retrieval classes

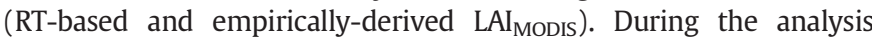

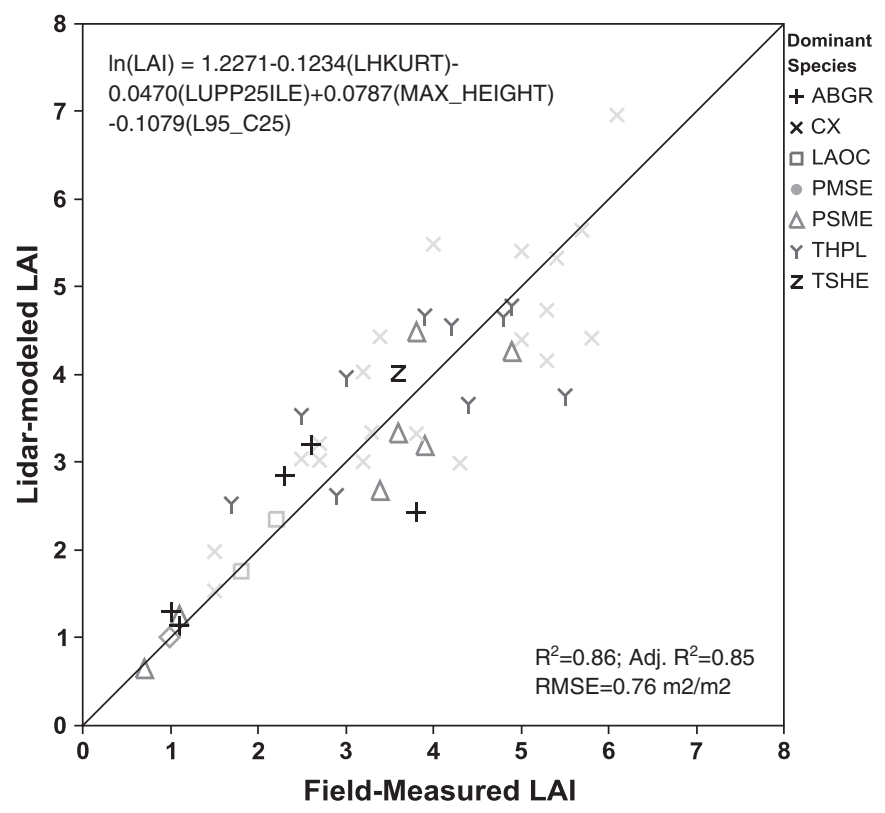

Fig. 3. Scatterplot of 1:1 relationship between field-measured vs. lidar-modeled LAI. Symbols represent dominant species per plot. LHKURT corresponds to the kurtosis statistic for lidar derived heights extracted from each $30 \mathrm{~m}$ sample plot; LUPP25ILE is the upperstory 25th percentile height; MAX_HEIGHT is the maximum lidar-derived height in a plot; L95_C25 refers to the vertical distance between the 95th percentile upperstory height and 25th percentile total canopy height.

period, JD-specific LAI MODIS consistently overestimated LAI $_{\text {LIDAR }}$ ( $\mu=3.3$ LAI, $\sigma=0.8$ ) by 0.2 LAI to 1.2 LAI units. Based on Tukey's HSD tests, many $\mathrm{LAI}_{\mathrm{MODIS}}$ mean values were significantly different $(\alpha=0.05)$, as denoted by separate letter subscripts, from one composite date to the next as well as from the LAI $_{\text {LIDAR }}$ dataset. Since the time period of analysis is focused on maximum greenness for the study area, we expect that mean $\mathrm{LAI}_{\text {MODIs }}$ values would not significantly differ between composite periods. The LAI LIDAR $_{\text {dataset was assumed as }}$ the study area benchmark value such that mean bias error and RMSE values for the LAI MODIS JD composites were compared directly to the LAI $_{\text {LIDAR }}$ study area mean. Although LAI MODIs values for the study area by JD composite exhibited similar ranges in retrieved LAI values, differences (mean bias errors and sums of squared errors)

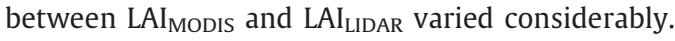

\section{3. $L A I_{M O D I S}$ performance by retrieval algorithm}

To further evaluate the $\mathrm{LAI}_{\text {MODIs }}$ product for our study area, we

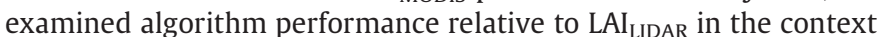
of specific retrieval quality classes. The proportion of study area pixels $(n=556)$ used to compile the LAI $\mathrm{I}_{\text {MODIS }}$ composite product for each 8-day period in 2003 is summarized in Fig. 6. While the $\mathrm{RT}_{\text {MAIN }}$ algorithm constitutes the vast majority of retrievals annually, $\mathrm{RT}_{\mathrm{SAT}}$ and $\mathrm{EMP}_{\mathrm{NDVI}}$-based retrievals contribute a large proportion of pixels to the composite products during the summer months and period of maximum greenness.

The scatterplots shown in Fig. 7a-e represent the 1:1 relationships between LAI $\mathrm{LIDAR}_{\text {and }}$ and $\mathrm{LAI}_{\text {MODIS }}$ for each $\mathrm{LAI}_{\text {MODIS }}$ composite. Based on the frequency of red ( $\left.\mathrm{RT}_{\mathrm{MAIN}}\right)$, green $\left(\mathrm{RT}_{\mathrm{SAT}}\right)$, and blue $\left(\mathrm{EMP}_{\mathrm{NDVI}}\right)$ symbols it is evident that $\mathrm{RT}_{\text {MAIN }}$ retrievals are predominantly used to populate each composite product for JD201 (55\%), JD 217 (64\%), and JD 233 (60\%), while JD 209 (47\%) and JD 225 (36\%) exhibit a larger proportion of $\mathrm{EMP}_{\mathrm{NDVI}}$ and $\mathrm{RT}_{\mathrm{SAT}}$ retrievals, respectively. JD 209 had the greatest percentage of EMP ${ }_{\mathrm{NDVI}}$ retrievals (38\%) and JD 225 retrievals were primarily of $\mathrm{RT}_{\mathrm{SAT}}$ quality $(47 \%)$. Based on the composite products we evaluated, the $\mathrm{LAI}_{\text {MODIS }} \mathrm{RT}_{\text {MAIN }}$ algorithm is rarely used to retrieve LAI values greater than 4 LAI and for 


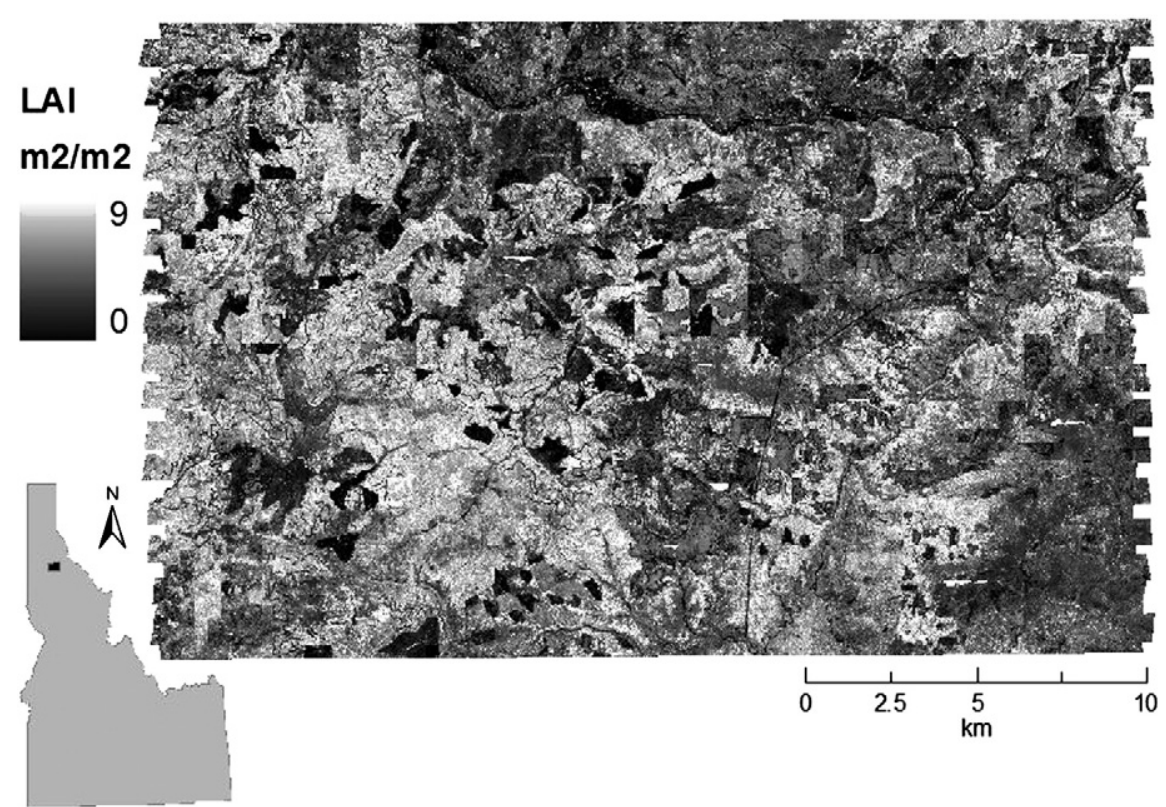

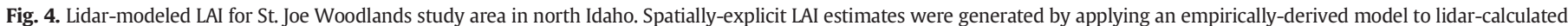
vegetation height and cover metrics at $30 \mathrm{~m}$ spatial resolution.

the entire range of LAI values, considerable overestimation of LAI (relative to lidar-derived LAI) occurred when either the $\mathrm{RT}_{\mathrm{SAT}}$ or EMP $_{\text {NDVI }}$ algorithms were employed. Fig. $7 f$ provides an overview of the performance across the five composite periods for LAI $\mathrm{LIDAR}_{\mathrm{L}}$ plotted against $\mathrm{LAI}_{\Delta}$. For all composite dates, $\mathrm{RT}_{\text {MAIN }}$ retrievals provided the best agreement with LAI IIDAR $_{\text {Limates; with general }}$

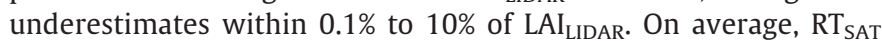
and $\mathrm{EMP}_{\mathrm{NDVI}}$ overestimated $\mathrm{LAI}_{\mathrm{LIDAR}}$ by $32 \%(+/-16)$ and $27 \%$ $(+/-12)$, respectively for the pixels and composite periods under consideration.

3.4. Influence of sub-pixel structural complexity on algorithm-specific retrieval frequency and $L A I_{\Delta}$

The five composite periods of our analysis were concatenated into one dataset to determine if consistent factors could be identified that either a) increased the frequency of retrievals within a specific algorithm quality class, or b) influenced the magnitude of $\mathrm{LAI}_{\Delta}$.

Fig. $8 \mathrm{a}$ and $\mathrm{c}$ provides a different perspective of the same information presented in Fig. 7f. Specifically, the majority of retrievals over the five composite periods were retrieved using the $\mathrm{RT}_{\text {MAIN }}$ algorithm (Fig. 8a). For low-to-moderate LAI ( $\leq 4 \mathrm{LAI})$ values, the RT $\mathrm{MAIN}_{\text {tends }}$ to perform well, where mean $\mathrm{LAI}_{\Delta}$ ranges between $+/-1$ LAI. However, as $\mathrm{LAI}_{\text {LIDAR }}$ increases, the frequency of $\mathrm{RT}_{\text {MAIN }}$ retrievals decrease and $\mathrm{LAI}_{\Delta}$ calculated from the $\mathrm{RT}_{\mathrm{MAIN}}$ class trends toward large underestimates averaging $2.8 \mathrm{~m}^{2} / \mathrm{m}^{2}(+/-1.1)$ for $\mathrm{LAI} \geq 5$ (Fig. $8 \mathrm{c}$ ). $\mathrm{RT}_{\text {SAT }}$ and $\mathrm{EMP}_{\mathrm{NDVI}}$ retrieval frequency increased for pixels with $\mathrm{LAI}_{\mathrm{LIDAR}} \geq 3$ LAI, though the average underestimate for that class decreased as LAI $_{\text {LIDAR }}$ increased. Across the entire range of LAI, the average overestimate for $\mathrm{RT}_{\mathrm{SAT}}$ and $\mathrm{EMP}_{\mathrm{NDVI}}$ retrieval classes was approximately $2 \mathrm{~m}^{2} / \mathrm{m}^{2}(+/-0.8)$.

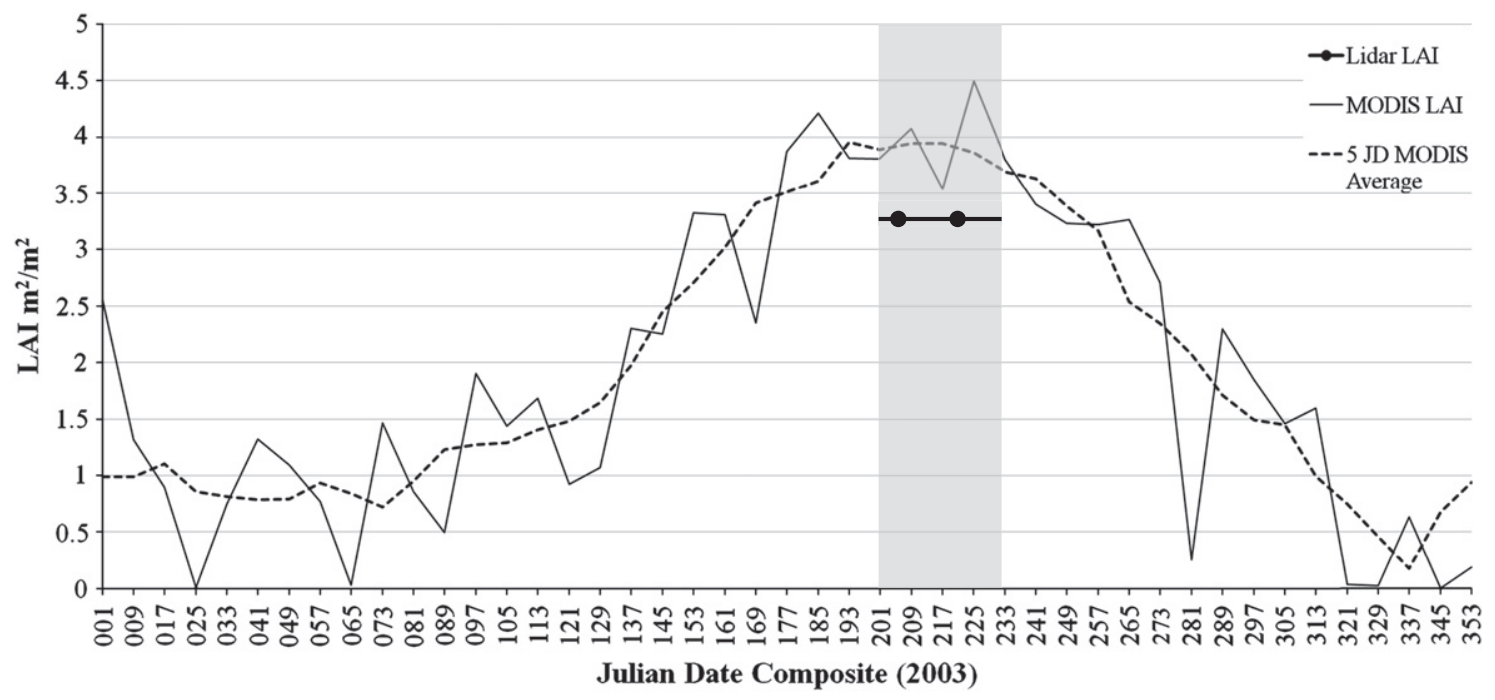

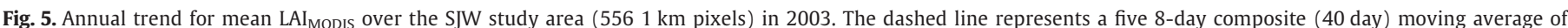

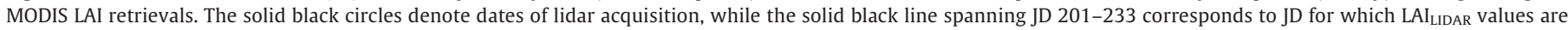

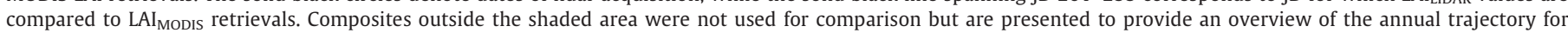
mean LAI values from MODIS for our study area. 
Table 2

Univariate LAI statistics for entire study area and bias errors for LAI $_{\text {LIDAR }}$ estimates and $\mathrm{LAI}_{\text {MODIS }}$ retrievals.

\begin{tabular}{|c|c|c|c|c|c|c|c|}
\hline Variable & $\mathrm{n}$ & $\mu^{*}$ & $\sigma$ & Range & $\begin{array}{l}\text { Mean } \\
\text { bias } \\
\text { error }\end{array}$ & $\begin{array}{l}\text { Sum } \\
\text { squared } \\
\text { error (SSE) }\end{array}$ & $\begin{array}{l}\text { Root mean } \\
\text { squared error } \\
\text { (RMSE) }\end{array}$ \\
\hline JD_201 & 556 & $3.8_{\mathrm{b}, \mathrm{c}}$ & 1.5 & $0.7-6.8$ & $0.5_{\mathrm{b}}$ & 1816.7 & 1.7 \\
\hline JD_209 & 556 & $4.1_{\mathrm{b}}$ & 1.5 & $1.5-6.8$ & $0.8_{\mathrm{c}}$ & 1697.4 & 1.5 \\
\hline JD_217 & 556 & $3.5_{\mathrm{c}, \mathrm{d}}$ & 1.5 & $0.5-6.8$ & $0.2 \mathrm{a}$ & 1473.5 & 1.6 \\
\hline JD_225 & 556 & $4.5 \mathrm{a}$ & 1.4 & $0.7-6.6$ & $1.2_{\mathrm{d}}$ & 2027.8 & 1.8 \\
\hline JD_233 & 556 & $3.8_{\mathrm{b}, \mathrm{c}}$ & 1.2 & $1.1-6.8$ & $0.5_{\mathrm{b}}$ & 1105.7 & 1.2 \\
\hline $\mathrm{LAI}_{\text {LIDAR }}$ & 556 & $3.3_{\mathrm{d}}$ & 0.8 & $0.5-5.7$ & $\mathrm{~N} / \mathrm{A}$ & $\mathrm{N} / \mathrm{A}$ & $\mathrm{N} / \mathrm{A}$ \\
\hline FIELD_DATA & 46 & $3.4_{d}$ & 1.5 & $0.7-6.1$ & $\mathrm{~N} / \mathrm{A}$ & $\mathrm{N} / \mathrm{A}$ & N/A \\
\hline
\end{tabular}

* Different letters indicate a significant difference in means based on Tukey's Honestly Significant Difference multiple comparison tests and are specific within each column $(\alpha=0.05)$.

In Fig. 8b and d, we examine the influence of sub-pixel heterogeneity in LAI by examining retrieval frequency and $\mathrm{LAI}_{\Delta}$ as a function of the coefficient of variation (CV) in $30 \mathrm{~m} \mathrm{LAI}_{\text {LIDAR }}$ cells that were averaged for purposes of comparison with LAI MODIs. Results indicate that for very low CV values, all three algorithm retrieval classes were employed with near-equal frequency. In the middle range (50\% CV), near where the total pixel frequency distribution in CV peaks, the $\mathrm{RT}_{\text {MAIN }}$ and $\mathrm{RT}_{\mathrm{SAT}}$ algorithms are employed equally as often, although absolute mean $\mathrm{LAI}_{\Delta}$, is smaller for $\mathrm{RT}_{\text {MAIN }}$ than for $\mathrm{RT}_{\text {SAT. }}$. For CV values above $50 \%$, the $\mathrm{RT}_{\text {MAIN }}$ algorithm is employed more frequently. Minimal differences were observed in mean $\mathrm{LAI}_{\Delta}$ for pixels retrieved using $\mathrm{RT}_{\mathrm{SAT}}$ or $\mathrm{EMP}_{\mathrm{DNVI}}$ over the range of $\mathrm{LAI}_{\mathrm{LIDAR}}$ $\mathrm{CV}$ values. Pixels retrieved for these algorithm classes consistently

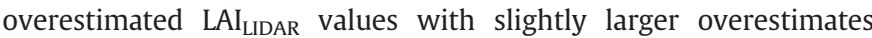
from the $\mathrm{RT}_{\mathrm{SAT}}$ retrieved pixels.

Algorithm-specific retrieval class frequency as a function of mean lidar height (Fig. 9a) and the CV of height (Fig. 9b) within each $1 \mathrm{~km}$ pixel were also examined to determine if vertical structural complex-

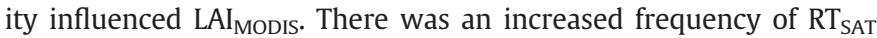
and EMP $_{\mathrm{NDVI}}$ retrievals as height increased up to $20 \mathrm{~m}$ mean canopy height. For pixels with a mean canopy height greater than $20 \mathrm{~m}$, the $\mathrm{RT}_{\mathrm{SAT}}$ or $\mathrm{EMP}_{\mathrm{DNVI}}$ algorithms were employed more often. We did not observe clear relationships between frequencies by retrieval algo-

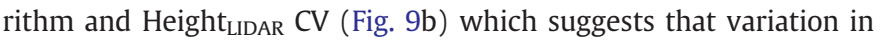

vertical structure within the $1 \mathrm{~km}$ MODIS pixel did not influence the preferential retrieval of a specific algorithm class.

Fig. 9c and d depicts mean $\mathrm{LAI}_{\Delta}$ over the range of mean lidar

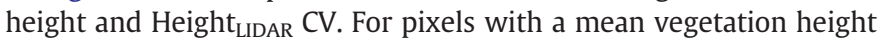
up to $15 \mathrm{~m}, \mathrm{LAI}_{\text {MODIS }}$ retrieved by $\mathrm{RT}_{\text {MAIN }}$ tends to average zero $\mathrm{LAI}_{\Delta}$. However, as height increases $\mathrm{RT}_{\text {MAIN }}$ retrieved pixels trend toward large underestimates, while $\mathrm{RT}_{\mathrm{SAT}}$ and $\mathrm{EMP}_{\mathrm{NDVI}}$ retrievals continue to exhibit a trend of consistent overestimation. As seen with LAI LIDAR $\mathrm{CV}, \mathrm{RT}_{\text {MAIN }}$ retrievals exhibit the largest underestimates at low

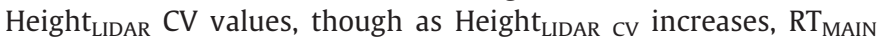
retrievals trend toward slight overestimation. The primary consistent relationship we observed with $\mathrm{LAI}_{\text {MODIS }}$ retrieval class and $\mathrm{LAI}_{\Delta}$ was the tendency for $\mathrm{RT}_{\mathrm{SAT}}$ retrievals to overestimate $\mathrm{LAI}_{\text {LIDAR }}$ across the range of Height $t_{\text {LIDAR }}$ CV values; oftentimes average overestimates were slightly higher than $\mathrm{EMP}_{\mathrm{NDVI}}$-based retrievals.

Algorithm retrieval class frequencies and $\mathrm{LAI}_{\Delta}$ are shown as a function of terrain complexity, or VRM CV, in Fig. 10a and b. We did not identify obvious relationships between MODIS algorithm pathway retrieval class or performance based on this measure of sub-pixel landscape heterogeneity.

\subsection{Influence of sun/sensor angles on algorithm-specific retrieval frequency and $L A I_{\Delta}$}

Summarized in Fig. 11a and c are the relationships between algorithm-specific retrieval frequency and mean $\mathrm{LAI}_{\Delta}$ over the range of solar zenith angles (SOLZ) applicable to our study period. The $\mathrm{RT}_{\text {MAIN }}$ algorithm tends to retrieve the majority of pixels for SOLZ up to approximately $35^{\circ}$ whereas the $\mathrm{RT}_{\mathrm{SAT}}$ and $\mathrm{EMP}_{\mathrm{NDVI}}$ retrievals increase for SOLZ greater than $35^{\circ}$. For lower SOLZ over our study area, the magnitude of $\mathrm{LAI}_{\Delta}$ for $\mathrm{RT}_{\text {MAIN }}$ retrievals is considerable at lower SOLZ angles, though it should be noted that the range of SOLZ is relatively small. As with our measure of terrain complexity, for $\mathrm{RT}_{\mathrm{SAT}}$ and $\mathrm{EMP}_{\mathrm{NDVI}}$ retrieval classes, SOLZ angle does not appear to have an influence on the magnitude of $\mathrm{LAI}_{\Delta}$ for the range of SOLZ values during our analysis period.

The same sets of relationships for sensor zenith angle (SENZ) are provided in Fig. 11b and d. According to Fig. 11b there is an increased frequency of $\mathrm{RT}_{\mathrm{SAT}}$-based retrievals at $10^{\circ}$ and $60^{\circ} \mathrm{SENZ}$. Similar to SOLZ, SENZ angles do not appear to influence $\mathrm{LAI}_{\Delta}$ for $\mathrm{RT}_{\mathrm{SAT}^{-}}$or $\mathrm{EMP}_{\mathrm{NDVI}}$-based retrievals. However, $\mathrm{RT}_{\text {MAIN }}$ retrievals are influenced

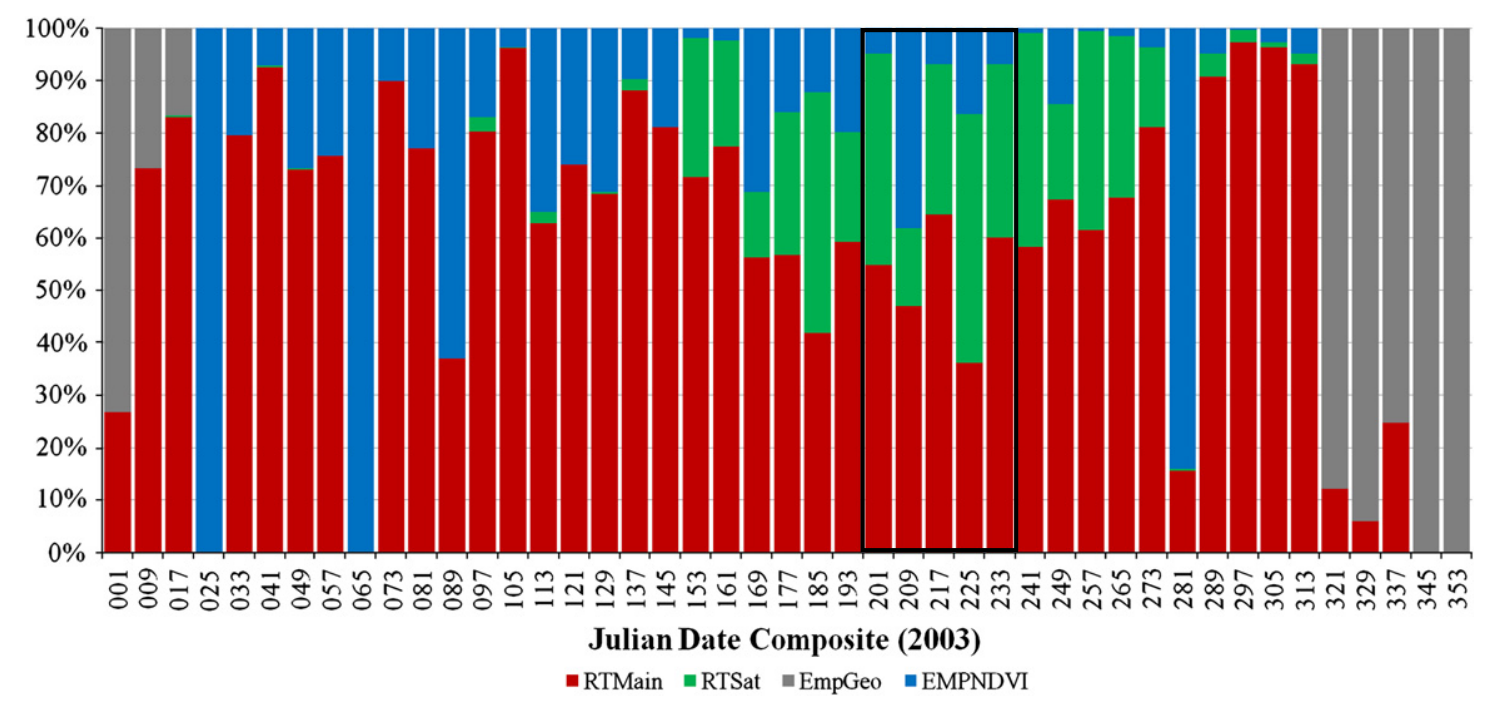

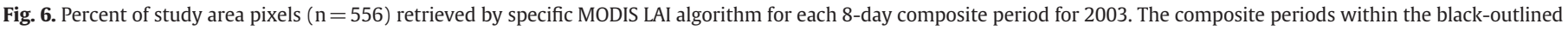

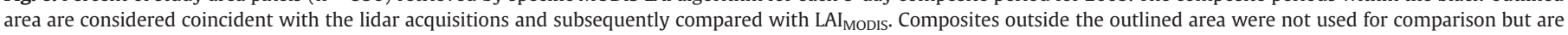
presented to provide an overview of the annual pattern for algorithm retrieval class for the study area. 

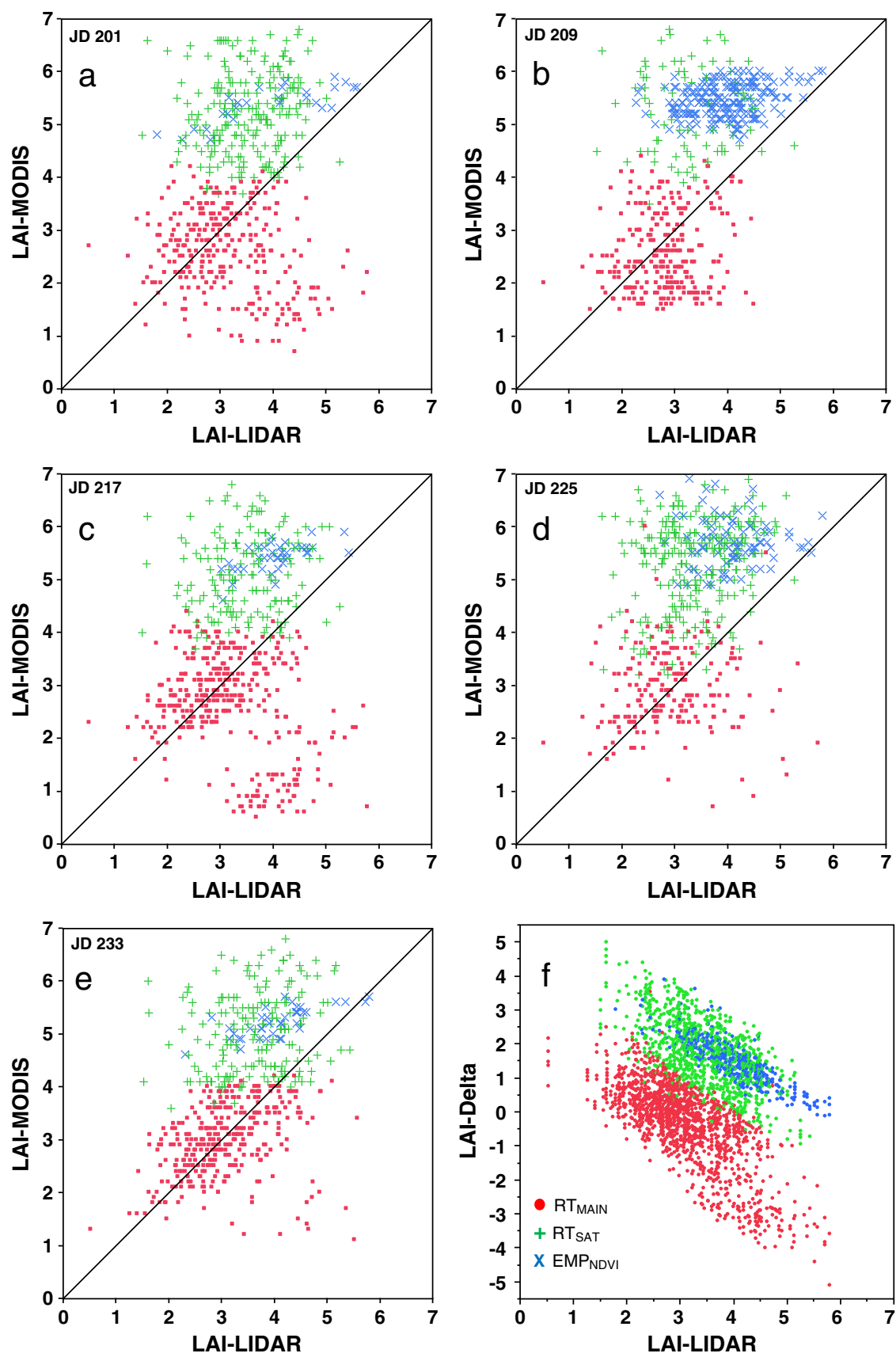

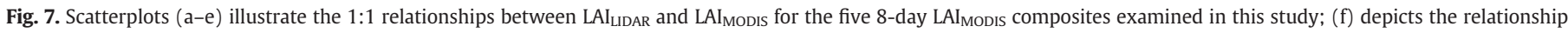
between $\mathrm{LAI}_{\Delta}$ and $\mathrm{LAI}_{\mathrm{LIDAR}}$ for all composited pixels in the 40-day analysis period.

as SENZ increases, except that the average $\mathrm{LAI}_{\Delta}$ is significantly low (near $0 \%$ ) at $60^{\circ} \mathrm{SENZ}$ (where few $\mathrm{RT}_{\text {MAIN }}$ pixels are retrieved) and considerably high at $70^{\circ} \mathrm{SENZ}\left(\mathrm{LAI}_{\triangle}\right.$ approximately 1.7 ). Further

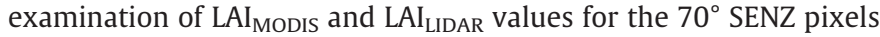
revealed a tendency for the $\mathrm{RT}_{\text {MAIN }}$ algorithm to return a $\mathrm{LAI}$ solution of $<=1$, while $\mathrm{LAI}_{\text {LIDAR }}$ values ranged between 2.9 and 5.7.

Fig. 12a and b summarizes the relationships between algorithmspecific retrieval frequency and mean $\mathrm{LAI}_{\Delta}$ for sensor azimuth angle (SENA). Specific relationships between SENA and the frequency of $\mathrm{RT}_{\text {MAIN }}$ retrievals versus $\mathrm{RT}_{\mathrm{SAT}}$ are evident at opposite ends of the SENA range. Fig. 12a displays a higher frequency of $\mathrm{RT}_{\text {MAIN }}$ retrievals for LAI derived from forward scatter conditions while the frequency of $\mathrm{RT}_{\text {SAT }}$ retrievals increases considerably in backscatter situations. The magnitude of mean $\mathrm{LAI}_{\triangle}$ over the range of SENA does not vary considerably by retrieval algorithm, particularly for $\mathrm{RT}_{\mathrm{SAT}}$ and $\mathrm{EMP}_{\mathrm{NDVI}}$-based LAI retrievals. $\mathrm{RT}_{\mathrm{MAIN}}$ retrievals, however, do exhibit higher variance in forward scatter situations, though mean $\mathrm{LAI}_{\Delta}$ remains relatively low.

\section{Discussion}

\subsection{LAI comparisons by retrieval class}

Here we separated the RT-based retrievals into their respective pathways (main and saturated) and examined the agreement between the applicable algorithm quality classes for the five JD composites. Essentially, we assessed $\mathrm{LAI}_{\Delta}$ per pixel based on three algorithm-specific retrieval classes. We found that there was little 

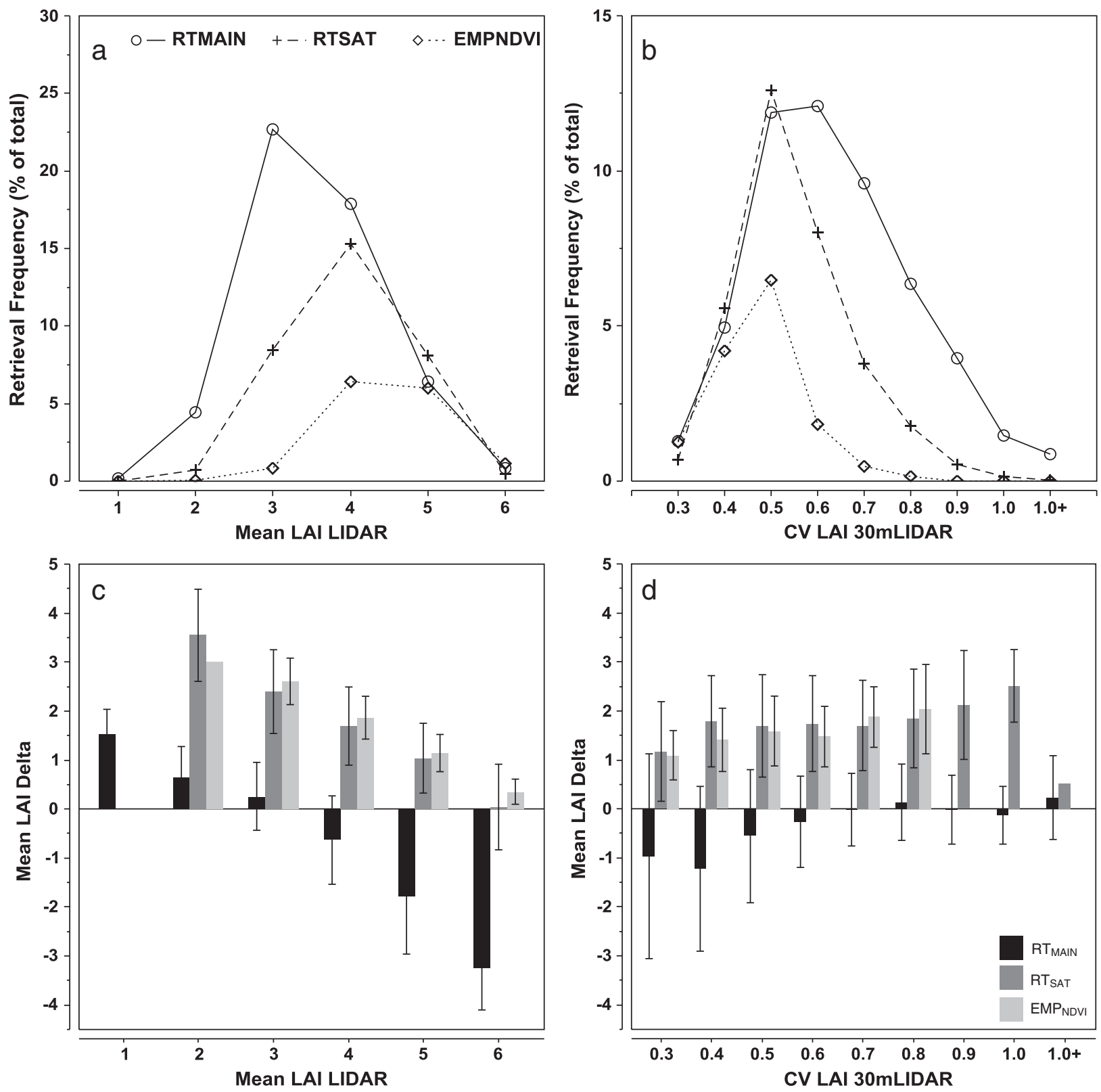

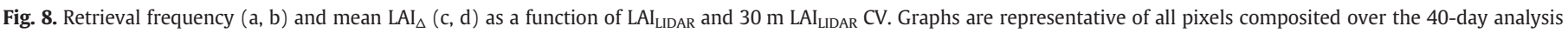
period and grouped by algorithm-specific retrieval class.

consistency in retrieval quality class for the same pixels among the five composite periods; only $19 \%$ of pixels were retrieved using the same retrieval quality class over the five composite periods ( $16 \%$ was consistently retrieved with $\mathrm{RT}_{\text {MAIN }}$ and $3 \%$ with $\mathrm{RT}_{\mathrm{SAT}}$ ).

Many prior LAI comparisons have examined MODIS retrieval quality by grouping $\mathrm{RT}_{\mathrm{MAIN}}$ and $\mathrm{RT}_{\mathrm{SAT}}$ retrievals as "good" or "main" algorithm retrievals and $\mathrm{EMP}_{\mathrm{GEO}}$ or $\mathrm{EMP}_{\mathrm{NDVI}}$ retrievals as "backup." If we characterize the MODIS LAI pixels based on this level of quality classification, the proportion of main algorithm retrievals for our study is greater than $60 \%$ (Fig. 6). Interpretation of information presented in Table 2 and Fig. 7a-e reveals a tendency for study area means to

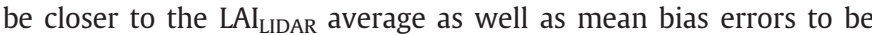
lower for composite dates that include a higher proportion of $\mathrm{RT}_{\text {MAIN }}$ retrievals (e.g. JD 217 and JD 233). These results support findings of De Kauwe et al. (2011), who used only $\mathrm{RT}_{\text {MAIN }}$ retrievals and found that the $\mathrm{C} 5$ product underestimated Landsat EMT + derived LAI in a mixed conifer ecosystem. We propose that when the RT-retrieved pixels are grouped into the same class (with and without saturation) and comparisons of MODIS versus field-observed and mapped LAI estimates are made based on that classification scheme (e.g. Cohen et al., 2003; Hill et al., 2006; Heinsch et al., 2006; Pisek \& Chen, 2007), the results may be biased toward better agreement for composite products with a larger proportion of $\mathrm{RT}_{\text {MAIN }}$ retrievals in low-to-moderate LAI ecosystems.

These results are relevant because a noted improvement of the current version of the $\mathrm{LAI}_{\text {MODIS }}$ product ( $\mathrm{C} 5$ ) from previous collections is the increased frequency of main algorithm retrievals (both $\mathrm{RT}_{\text {MAIN }}$ and $\mathrm{RT}_{\mathrm{SAT}}$ ) used to generate the daily LAI product (i.e., fewer $\mathrm{EMP}_{\mathrm{NDVI}}$ retrievals) and subsequently employed to populate the composite products. In a recent analysis the temporal and spatial variability of the C5 LAI/fPAR product over a 1.1 million $\mathrm{km}^{2}$ area dominated by temperate forests, Steinberg and Goetz (2009) found that the C5 product provided increased spatial coverage of $\mathrm{RT}_{\text {MAIN }}$ retrievals compared to the previous collection, however, both broadleaf and evergreen needleleaf forests still exhibited a greater percentage of $\mathrm{RT}_{\mathrm{SAT}}$ and backup algorithm retrievals. For our analysis, JD 209 and JD 

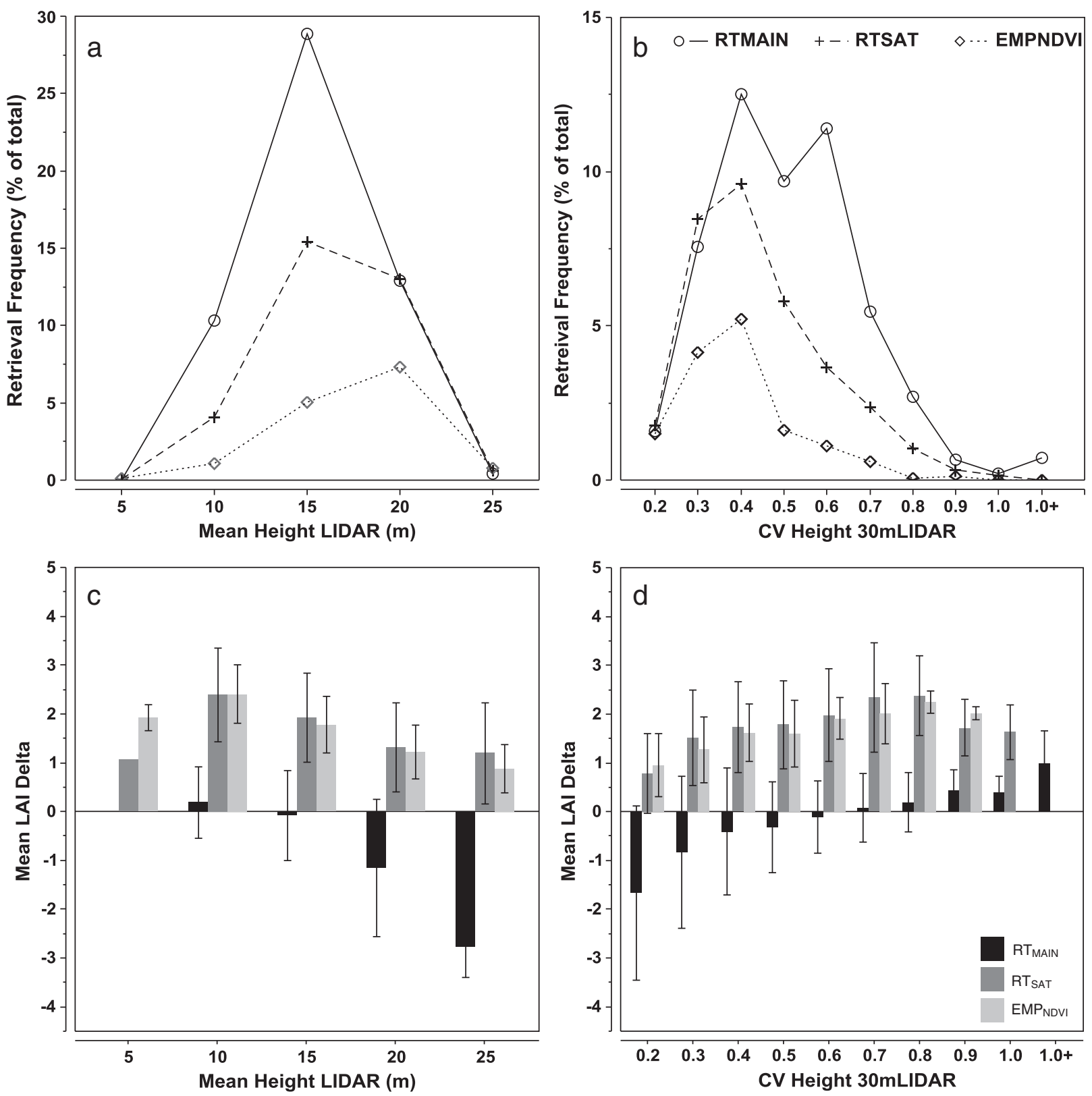

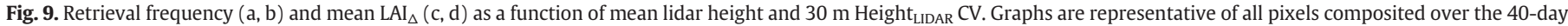
analysis period and grouped by algorithm-specific retrieval class.

225 , which have a greater combined proportion of $\mathrm{EMP}_{\mathrm{NDVI}}$ and $\mathrm{RT}_{\mathrm{SAT}}$ retrievals, exhibit the largest means and mean bias errors of all periods we examined. $\mathrm{RT}_{\mathrm{SAT}}$ and $\mathrm{EMP}_{\mathrm{NDVI}}$ retrievals consistently overestimated $\mathrm{LAI}_{\mathrm{LIDAR}}$ values by up to $75 \%\left(\mathrm{RT}_{\mathrm{SAT}}\right)$ and $73 \%\left(\mathrm{EMP}_{\mathrm{NDVI}}\right)$. The general trend in over/underestimates based on retrieval quality class is similar to Cohen et al. (2006) who examined algorithm-specific pathways and LAI ${ }_{\text {MODIS }}$ over nine BigFoot study sites from 2000 to 2003 using Collection 4 datasets. Though not the primary objective of their paper, they specifically noted that $\mathrm{RT}_{\text {MAIN }}$ retrievals provided the lowest LAI estimates and $\mathrm{RT}_{\mathrm{SAT}}$ the highest for their tall grass and cropland sites, which are relatively low LAI ecosystems. However, their interpretation could also be extended to their mixed forest and northern boreal sites based on the figures provided in their manuscript.

Based on our analysis within the SJW and during the time period under consideration, our results suggest that $\mathrm{RT}_{\mathrm{SAT}}$ performs as well as $\mathrm{EMP}_{\mathrm{NDVI}}$ retrievals, which is counterintuitive to the quality flags and recommended use of the product. Yang et al. (2006c) clarify that barring main algorithm failure, $\mathrm{RT}_{\mathrm{MAIN}}$ is employed in the case of low $\mathrm{LAI}(<3)$ and $\mathrm{RT}_{\mathrm{SAT}}$ retrievals are obtained when surface reflectance saturates. Unfortunately, surface reflectance tends to saturate and lower quality retrievals are used in the composite products during peak photosynthetic periods, when accurate estimates of LAI are critical for subsequent ecosystem modeling. Based on our case study, we suggest that combining all RT-based LAI retrievals for subsequent modeling may introduce additional bias with respect to analysis outputs when coarse-resolution LAI is relatively low (i.e., $<3-4$ LAI) and a significant proportion of the composite product has been populated with $\mathrm{RT}_{\mathrm{SAT}}$-retrieved pixels.

\subsection{Influence of vegetation structural heterogeneity on pixel-based comparisons}

The SJW study area is a highly managed forest landscape. Values of $\mathrm{LAI}_{\Delta}$ were greatest for the $\mathrm{RT}_{\text {MAIN }}$ algorithm at low values of $\mathrm{LAI}_{\text {LIDAR }}$ $\mathrm{CV}(\leq .40$; Fig. $8 \mathrm{~d})$. This is likely due to the fact that in this study area, such pixels tend to be comprised of homogeneous stands of 

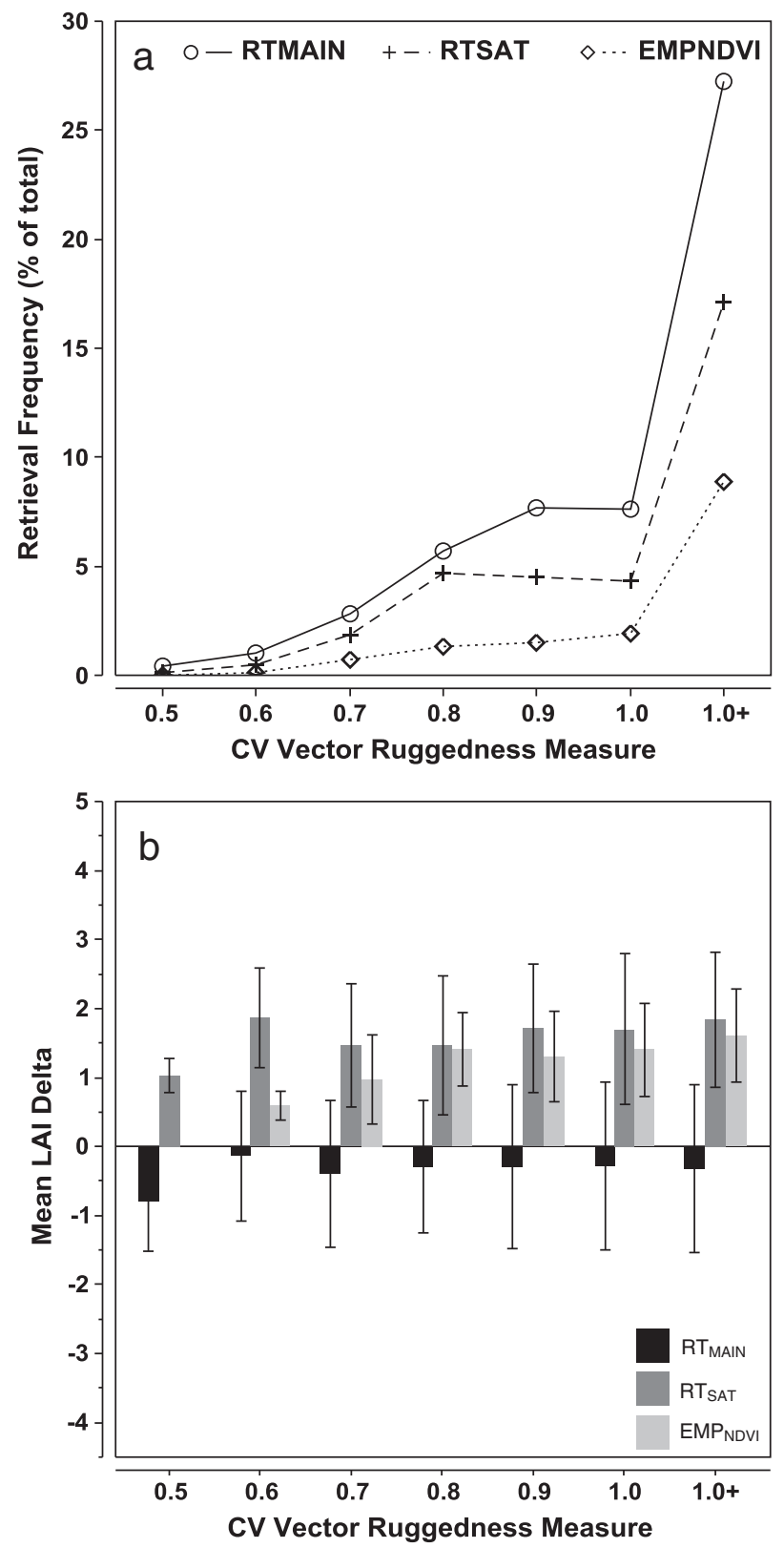

Fig. 10. Retrieval frequency (a) and mean $\mathrm{LAI}_{\Delta}$ (b) as a function of $\mathrm{CV}$ of topographic vector ruggedness. Graphs are representative of all pixels composited over the 40-day analysis period and grouped by algorithm-specific retrieval class.

forest with larger LAI values (i.e., $\mathrm{LAI}>3$ ). The pixels with higher $\mathrm{CV}$ values tend to be comprised of a patchwork mix of dense stands and harvested areas representing, on average, pixels with lower biomass (i.e. smaller LAI values). As LAI $\mathrm{LIDAR}_{\mathrm{CV}} \mathrm{C}$ increases (and LAI $\mathrm{I}_{\text {LIDAR }}$ values decrease), $\mathrm{RT}_{\text {MAIN }}$ performance improves such that mean $\mathrm{LAI}_{\Delta}$ trends toward zero with standard deviations within +/-1 LAI unit.

Since the $\mathrm{RT}_{\text {MAIN }}$ algorithm does not inherently deal with sub-pixel variability, the relatively good performance of the $\mathrm{RT}_{\text {MAIN }}$ algorithm in these heterogeneous pixels may be the result of averaging of the multispectral response over the $1 \mathrm{~km}$ pixel. Jin et al. (2007) discussed the influence of averaging radiative signals over a coarse spatial resolution and the effects on $\mathrm{LAI}_{\text {MODIS }}$ solutions. They proposed to correct the $\mathrm{LAI}_{\text {MODIs }}$ product by quantifying sub-pixel distributed LAI and implemented sub-pixel land cover and LAI estimates from Landsat ETM + to improve the $\mathrm{LAI}_{\text {MODIs }}$ product. Though not tested or developed, similar approach to address within-pixel landscape heterogeneity could potentially be implemented using existing products such as the MODIS Vegetation Continuous Fields product (Hansen et al., 2003), or by incorporating vegetation structural characteristics derived from refined existing canopy height datasets (e.g., Lefsky, 2010.) or from future spaceborne active sensor missions that provide vegetation structural information.

\subsection{Consideration of sources of error and uncertainty}

\subsubsection{Temporal differences in LAI measurements and lidar acquisition}

In terms of the suitability of the lidar-modeled LAI and comparisons with MODIS LAI products, temporal discrepancies between the lidar and LAI data acquisition campaigns may contribute some uncertainty with respect to the applicability of our lidar-based LAI model to evaluate MODIS LAI products (i.e., the lidar data were acquired during the same time of year as the MODIS and field data to which they are compared, but lidar data were acquired in a different year). This temporal discrepancy was considered in our selection of LAI field plots and a choice to mitigate the issue was to only sample from forest stands that had not been treated or altered (e.g. cleared, thinned, windthrow, etc.) between data acquisition campaigns. Part of the rationale to continue sampling and modeling in the unaffected areas of the region was based on findings from other studies. Grier and Running (1977) recognized that LAI of conifer systems in the Pacific Northwest reached a steady state in early succession and Law et al. (2001) found that seasonal LAI values remained relatively stable for conifer ecosystems in eastern Oregon. As such and based on information from allometric equations and stand growth tables, increments in standing conifer biomass are minimal from year-to-year and should not significantly affect LAI values over a relatively short period of time for mid-to late-seral untreated stands.

The measurement and estimation errors of lidar data are minimal and contribute little bias in regard to model parameter estimates (Fig. 3). The use of lidar data to estimate and map LAI mitigates some concerns related to measurement bias introduced with traditional multispectral-based observations and resultant models used to validate MODIS LAI products (see Huang et al., 2006). It was not possible to identify an acceptable regression model for LAI for our study area from single-date multispectral data; the best SPOT5based spectral vegetation index model of the SJW resulted in $\mathrm{R}^{2}=0.49$ ( $\mathrm{RMSE}=2.7$ ) (Jensen et al., 2008). Though multispectral datasets indeed provide greater spatial coverage at higher temporal frequencies and considerably reduced costs, the insensitivity of a single multispectral image to provide enough information to address the structural complexity that drives LAI variation in this landscape with complex topography and vegetation structure supports our decision to empirically model LAI with the existing lidar dataset.

Moreover, lidar-modeled LAI mapped at $30 \mathrm{~m}$ (Fig. 4) exhibited a similar landscape pattern as observed in the field and fine resolution multispectral imagery. Since the lidar-based model we used to map LAI was statistically robust, the empirical transfer across a large continuous area (58,000 ha) minimized uncertainties for intercomparisons. Little uncertainty is added to the analysis due to aggregation of the $30 \mathrm{~m}$ lidar grid cells to $1 \mathrm{~km}$ via simple averaging because the model which relates lidar metrics to lidar-derived LAI is linear and the distribution of $30 \mathrm{~m}$ lidar-mapped LAI pixels $(n=954)$ within each larger MODIS pixel was normally distributed.

\subsubsection{Contributions of understory vegetation to MODIS LAI}

Considerations regarding discrepancies between $\mathrm{LAI}_{\mathrm{MODIS}}$ and LAI $_{\text {LIDAR }}$ may be partially attributed to contributions from understory vegetation for which the lidar-based models do not account for since we measured canopy LAI (e.g. LAI-2000 observations were acquired at $1.37 \mathrm{~m}$ ) in the field and the lidar-based model incorporates covariates representative of the upperstory vegetation. In their comparison of lidar-derived and MODIS fPAR products, Chasmer et al. (2008) noted 

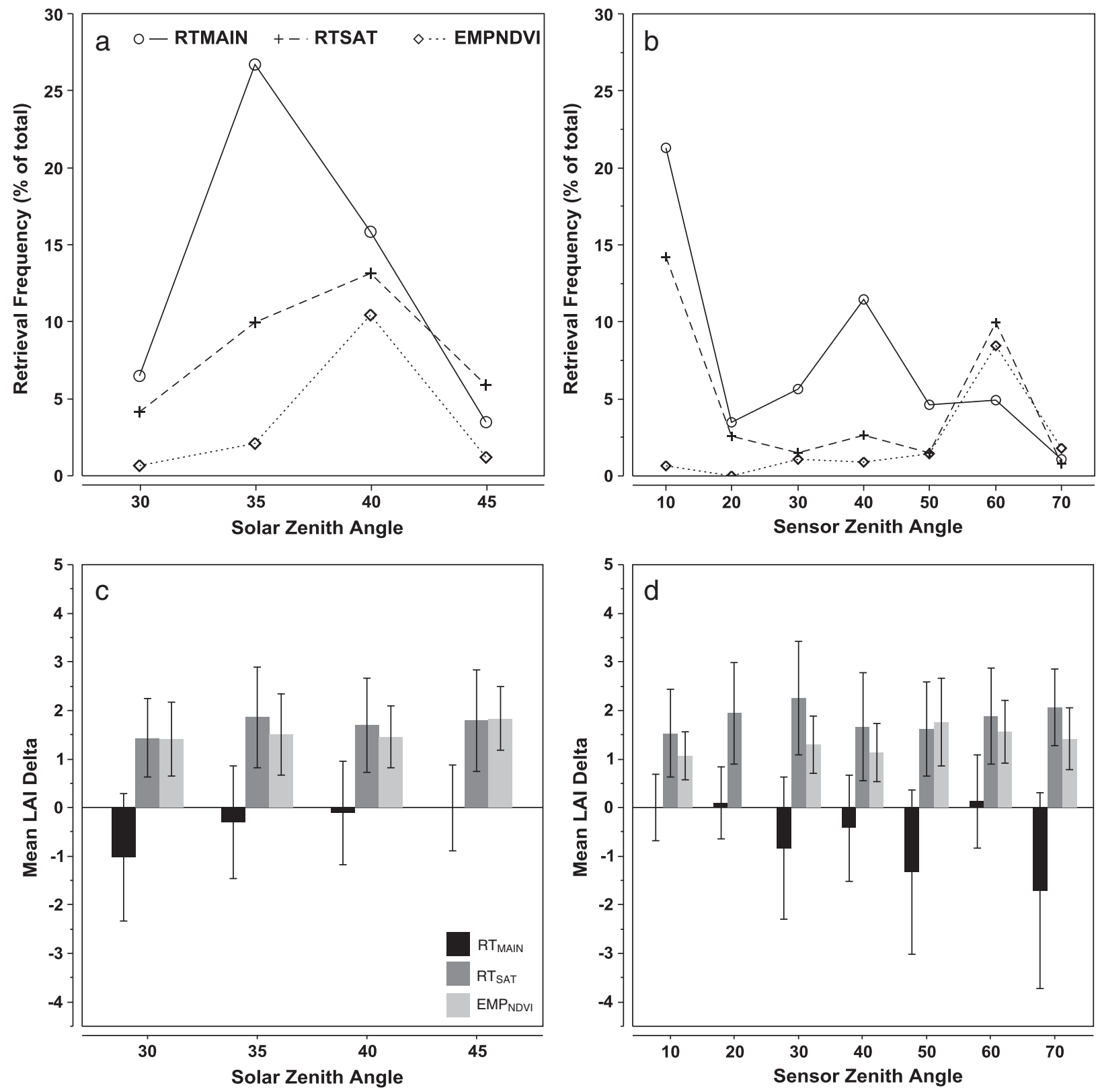

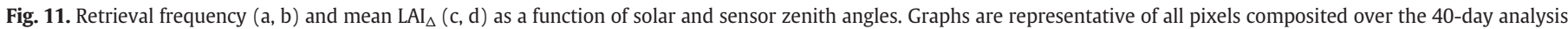
period and grouped by algorithm-specific retrieval class.

MODIS fPAR overestimates (up to 30\% for some pixels) in their study may have been attributed to the inability of their algorithm to separate low canopy cover lidar pulses from the terrain surface. In the context of this study, percent understory cover was not directly measured during the field campaign.

In terms of LAI retrievals, reflectance contributions from the understory vegetation in our study area likely contribute to the reflectance products utilized in the MODIS LAI algorithms, ultimately influencing canopy LAI retrievals. Such understory contributions are likely more conspicuous in open canopy stands where canopy transmittance increases and more understory vegetation is visible to the sensor. Steinberg et al. (2006) noted improved agreement between MODIS and fPAR estimates for sites with relatively high canopy density and greater discrepancies in areas where low canopy density facilitated increased reflectance contributions from understory vegetation. Additionally, Rautiainen (2005) reported a positive correlation between crown closure and percent LAI differences of inverted LAI and allometric LAI and Eriksson et al. (2006) reported improved relationships between canopy LAI and vegetation indices when canopy reflectance was separated from spectral contributions from the vegetation understory.

Further research could examine the degree to which lidar-modeled understory vegetation contributions influence MODIS LAI retrieval quality and product accuracy. In practice, lidar datasets have already been employed to characterize or differentiate between understory versus canopy vegetation contributions (Andersen et al., 2003; Hirata et al., 2003; Martinuzzi et al., 2009) and thus could lend utility in further quantifying additional vegetation structural characteristics not addressed in our study.

\subsubsection{Geolocation uncertainties and LAI comparisons}

Per-pixel comparisons have been traditionally discouraged due to geolocation issues. For instance, Wang et al. (2004) advised against pixel-by-pixel comparisons because such comparisons can result in poor correlations and instead advocated multi-pixel, patch-based comparisons to account for uncertainties in inputs to the LAl 

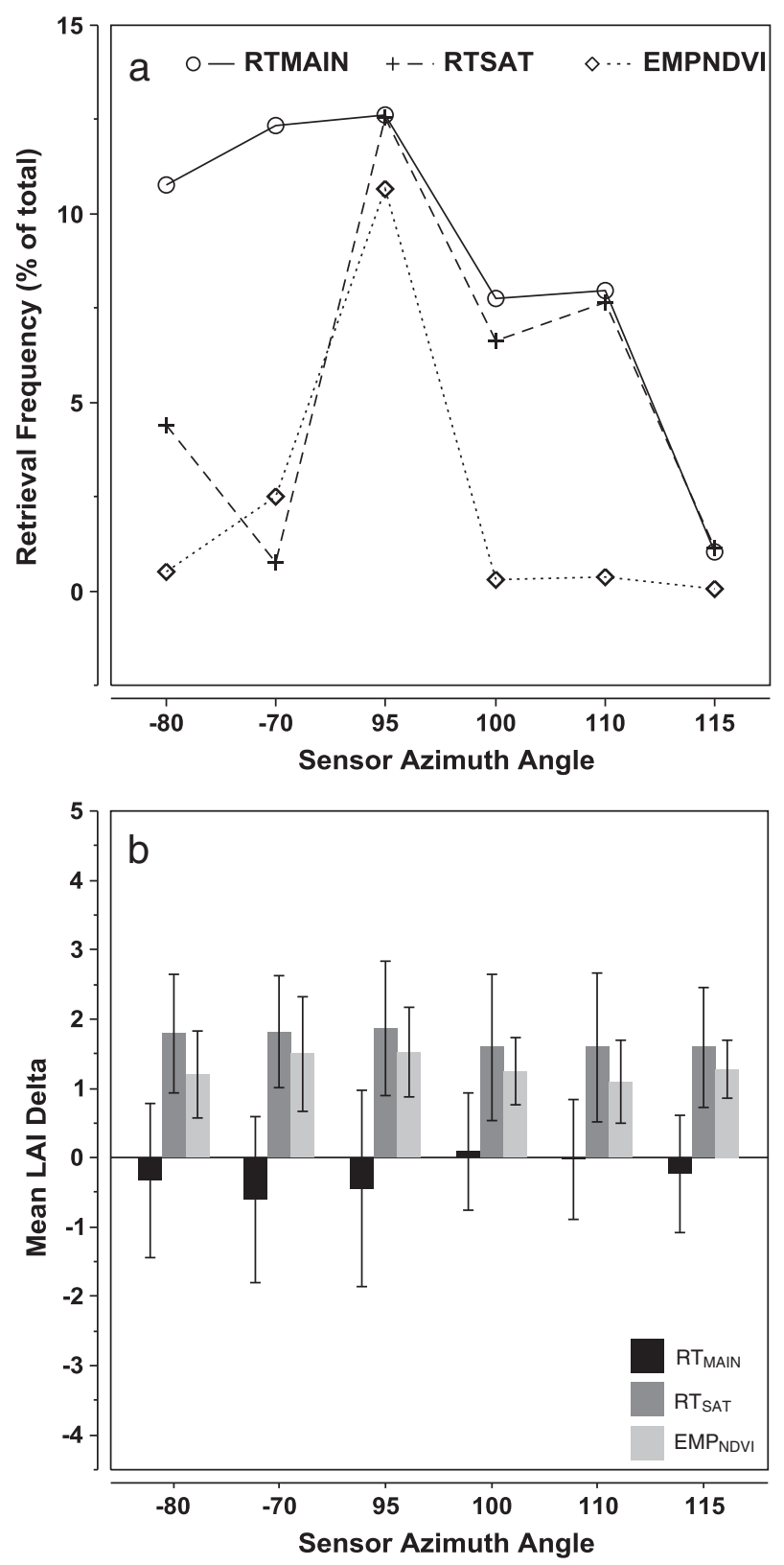

Fig. 12. Retrieval frequency (a) and mean $\mathrm{LAI}_{\Delta}$ (b) as a function of sensor azimuth angle. Graphs are representative of all pixels composited over the 40-day analysis period and grouped by algorithm-specific retrieval class.

algorithm. Yet, Pisek and Chen (2007) point out that validation isn't complete without a pixel-based comparison. Of particular importance with respect to per pixel accuracy is that spatially-explicit productivity models such as MOD17 NPP/GPP use individual pixel-based values of $\mathrm{LAI}_{\text {MODIS }}$ to estimate biomass, which is in turn used estimate autotrophic respiration. Since downstream data products rely on the individual pixels of each 8-day composite product, evaluation of pixel-based MODIS LAI performance seems particularly warranted.

The horizontal geolocational accuracy of airborne lidar systems is typically within $15-20 \mathrm{~cm}$ for conifer ecosystems, such as the SJW study area. Thus, we propose that geolocation issues in the context of our fine resolution LAI map are minimized due to the high positional accuracy of the sensor system. Whereas, the MODIS sensor has a geolocation goal of $50 \mathrm{~m}$ at nadir (Wolfe et al., 2002) this study does not take into account scan angle or geographic positional accuracies as they relate to the MODIS LAI product. Therefore we cannot quantify or characterize how geolocational uncertainties factor in to our assessment of $\mathrm{LAI}_{\Delta}$ for our study.

Further, it must be noted that the results of the analysis of sun and sensor angles are based on geolocation data provided in the MODIS Geolocation dataset (MOD03), which contains $1 \mathrm{~km}$ pixel-specific geodetic coordinates, ground elevation, solar and satellite zenith and azimuth angles (Nishihama et al., 1997). Unfortunately, although individual pixel data are provided, they only take into account the pixel-specific variations in the nominal Earth/Sun/sensor geometry across the time and space of a single MODIS scene. Therefore, they do not represent a calculation of pixel-specific effective solar or sensor angles based on the surface normal for each pixel. This is significant in a topologically-complex study area such as the SJW. Sun and sensor angles will ultimately affect surface reflectance, which is the primary input to the LAI algorithm. Uncertainties in the input surface reflectance can substantially affect LAI retrievals as noted by Tan et al. (2005). This issue is reported to be resolved in the Collection $5 \mathrm{LAI}_{\text {MODIS }}$ product by implementing band-specific thresholds on the input reflectance uncertainties used by the RT algorithm (Yang et al., 2006c). Our results indicate that sun/sensor geometry had minimal effect on the outcome of the LAI MODIS $-\mathrm{LAI}_{\text {LIDAR }}$ comparisons for our study area and period of analysis.

\section{Conclusion}

In this case study, a spatially-explicit, 30-m resolution lidar-derived grid of LAI values was aggregated to the resolution of the $1 \mathrm{~km}$ MODIS LAI product and used to perform an independent evaluation of $\mathrm{LAI}_{\mathrm{MODIS}}$ retrievals for a needleleaf forest with heterogeneous landscape and vegetation characteristics. We proposed that lidar-derived LAI estimates provided a more independent data source for evaluation of the LAI MODIS product compared to traditional multispectral sensor data that may be subject to the same shortcomings as MODIS for quantifying dense canopies. Moreover, lidar data provide better estimates over the entire range of field-measured LAI values since the data respond more directly to the structural characteristics of forest canopies and aren't subject to the same saturation issues commonly observed with passive optical sensors.

The primary findings of our analysis of five 8-day MODIS LAI composites revealed $\mathrm{LAI}_{\text {MODIS }}$ retrieved under ideal conditions (i.e., RTMAIN) resulted in an average underestimate of approximately $10 \%$ of LAI $_{\text {LIDAR }}$ over a range of landscape and vegetation structural conditions, however, for larger values of $\operatorname{LAI}_{\text {LIDAR }}(\geq 5) \mathrm{LAI}_{\text {MODIS }}$ underestimates increased to an average of approximately $50 \%$. The magnitude of MODIS $\mathrm{RT}_{\text {MAIN }}$ underestimates increased for $1 \mathrm{~km}$ pixels that exhibited large ( $\geq 20 \mathrm{~m}$ ) mean vegetation heights and for $1 \mathrm{~km}$ pixels that exhibited homogeneous vegetation structural conditions. Comparisons between $\mathrm{LAI}_{\mathrm{MODIS}}$ and $\mathrm{LAI}_{\mathrm{LIDAR}}$ for the $\mathrm{RT}_{\mathrm{SAT}}$ and $\mathrm{EMP}_{\mathrm{NDVI}}$ classes revealed consistent overestimates over the range of LAI and vegetation structural conditions, though both classes did perform better than $\mathrm{RT}_{\text {MAIN }}$ for $\mathrm{LAI} \geq 5$. Surprisingly, the two algorithm quality classes behaved in much the same manner regardless of within-pixel structural or sun/sensor geometry comparisons. Though $\mathrm{LAI}_{\text {MODIS }}$ re-

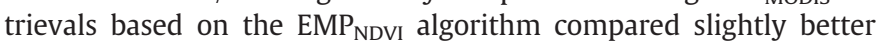
than $\mathrm{LAI}_{\mathrm{MODIS}}$ pixels retrieved with $\mathrm{RT}_{\mathrm{SAT}}$ quality, pixels from both quality classes exhibited average overestimates of $32 \%(+/-16)$ and $27 \%(+/-12)$ for $\mathrm{RT}_{\mathrm{SAT}}$ and $\mathrm{EMP}_{\mathrm{NDVI}}$, respectively, regardless of vegetation or landscape structural characteristics.

In summary, since lidar enables accurate descriptions of horizontal and vertical heterogeneity over a landscape, it lends itself to improved comparisons with MODIS and other course resolution LAI/fPAR data products (see Chasmer et al., 2008; Zhao \& Popescu, 2009). We believe this type of comparison should be replicated in other regions and biome types to provide additional insight regarding the accuracy and quality of LAI retrievals used for regional and global land surface monitoring and climate modeling. 


\section{Acknowledgments}

This research was supported by the NSF Idaho EPSCoR program grant EPS-447689, NASA Idaho Space Grant Consortium grant NGG-05GG29H, NASA EPSCoR grant NCC5-588, and a doctoral fellowship from the University of Idaho College of Graduate Studies. We would like to thank the Potlatch Corporation for allowing this research to be conducted on their lands, through association with the Sustainable Forestry component of Agenda 2020, a joint effort of the US Department of Agriculture Forest Service Research and Development and the American Forest and Paper Association. We also thank Drs. Yuri Knyazikhin and Ranga Myneni for clarification and feedback regarding the MODIS LAI product and this analysis. We thank Jeffrey Evans for lidar data processing, Caleb Jensen and Meghan Lonneker for collecting much of the LAI-2000 field data used in this study, and the 5 anonymous reviewers for their feedback and suggestions in improving this and an earlier version of the manuscript.

\section{References}

Allen, D. M. (1974). The relationship between variable selection and data augmentation and a method for prediction. Technometrics, 16, 127-127.

Andersen, H. -E., Foster, J., \& Reutebuch, S. E. (2003). Estimating forest structure parameters within Fort Lewis Military Reservation using airborne laser scanner (LIDAR) data. In Proceedings, 2nd Inter-national Precision Forestry Symposium (pp. 45-53). Seattle, Washington: University of Washington, College of Forest Resources.

Aragão, L. E. O. C., Shimabukuro, Y. E., Espírito-Santo, F. D. B., \& Williams, M. (2005). Spatial validation of the collection 4 MODIS LAI product in eastern Amazonia. IEEE Transactions on Geoscience and Remote Sensing, 43, 2526-2534

Baskerville, G. L. (1972). Use of logarithmic regression in the estimation of plant biomass. Canadian Journal of Forest Research, 2, 49-53.

Berterretche, M., Hudak, A. T., Cohen, W. B., Maiersperger, T. K., Gower, S. T., \& Dungan, J. (2005). Comparison of regression and geostatistical methods for mapping Leaf Area Index (LAI) with Landsat ETM + data over a boreal forest. Remote Sensing of Environment, 96, 49-61.

Bolstad, P., James, M., Vose, V., \& McNulty, G. (2001). Forest productivity, leaf area, and terrain in southern Appalachian deciduous forests. Forest Science, 47(3), 419-427.

Bonan, G. B. (1993). Importance of leaf area index and forest type when estimating photosynthesis in boreal forests. Remote Sensing of Environment, 43, 303-314.

Chasmer, L., Hopkinson, C., Treitz, P., McCaughey, H., Barr, A., \& Black, A. (2008). A lidar-based hierarchical approach for assessing MODIS fPAR. Remote Sensing of Environment, 112, 4344-4357.

Chen, J. M., \& Black, T. A. (1991). Measuring leaf area index of plant canopies with branch architecture. Agricultural and Forest Meteorology, 57, 1-12.

Chen, J. M., \& Chilar, J. (1995). Quantifying the effect of canopy architecture on optical measurements of leaf area index using two gap size analysis methods. IEEE Transactions on Geoscience and Remote Sensing, 33, 777-216.

Chen, J. M., \& Cihlar, J. (1996). Retrieving leaf area index of boreal conifer forests using Landsat TM images. Remote Sensing of Environment, 55, 153-162.

Chen, J. M., Rich, P. M., Gower, T. S., Norman, J. M., \& Plummer, S. (1997). Leaf area index of boreal forests: Theory, techniques and measurements. Journal of Geophysical Research, 102, 429-443.

Chen, X. X., Vierling, L., Deering, D., \& Conley, A. (2005). Monitoring boreal forest leaf area index across a Siberian burn chronosequence: A MODIS validation study. International Journal of Remote Sensing, 26, 5433-5451.

Chen, X. X., Vierling, L., Rowell, E., \& DeFelice, T. (2004). Using lidar and effective LAI data to evaluate IKONOS and Landsat 7 ETM + vegetation cover estimates in a ponderosa pine forest. Remote Sensing of Environment, 91, 14-26.

Clawges, R., Vierling, L. A., Calhoon, M., \& Toomey, M. P. (2007). Use of a ground-based scanning lidar for estimation of biophysical properties of western larch (Larix occidentalis). International Journal of Remote Sensing, 28, 4431-4344.

Cohen, W. B., \& Justice, C. O. (1999). Validating MODIS terrestrial ecology products: Linking in situ and satellite measurements. Remote Sensing of Environment, 70, 1-3.

Cohen, W. B., Maiersperger, T. K., Turner, D. P., Ritts, W. D., Pflugmacher, D., Kennedy, R. E., Kirschbaum, A., Running, S. W., Costa, M., \& Gower, S. T. (2006). MODIS land cover and LAI collection 4 product quality across nine sites in the western hemisphere. IEEE Transactions on Geoscience and Remote Sensing, 44, 1843-1857.

Cohen, W. B., Maiersperger, T. K., Yang, Z., Gower, S. T., Turner, D. P., Ritts, W. D., Berterretche, M., \& Running, S. W. (2003). Comparisons of land cover and LAI estimates derived from ETM+ and MODIS for four sites in North America: A quality assessment of 2000/2001 provisional MODIS products. Remote Sensing of Environment, 88, 233-255.

Curran, P. J. (1983). Multispectral remote sensing for the estimation of green leaf area index. Philosophical Transactions of the Royal Society of London A, 309, 257-270.

Curran, P. J., \& Williamson, H. D. (1987). Estimating the green leaf area index of grassland with airborne multispectral scanner data. Oikos, 49, 141-148.
De Kauwe, M. G., Disney, M. I., Quaife, T., Lewis, P., \& Williams, M. (2011). An assessment of the MODIS collection 5 leaf area index product for a region of mixed coniferous forest. Remote Sensing of Environment, 115, 767-780.

Duursma, R. A., Marshall, J. D., \& Robinson, A. P. (2003). Leaf area index inferred from solar beam transmission in mixed conifer forests on complex terrain. Agricultural and Forest Meteorology, 118, 221-236.

Eriksson, H. M., Eklundh, L., Kuusk, A., \& Nilson, T. (2006). Impact of understory vegetation on forest canopy reflectance and remote sensed LAI estimates. Remote Sensing of Environment, 103, 408-418.

Evans, J. S., \& Hudak, A. T. (2007). A multiscale curvature algorithm for classifying discrete return lidar in forested environments. IEEE Transactions on Geoscience and Remote Sensing, 45, 1029-1038.

Fensholt, R., Sandholt, I., \& Rasmussen, M. S. (2004). Evaluation of MODIS LAI, fPAR and the relation between fAPAR and NDVI in a semi-arid environment using in situ measurements. Remote Sensing of Environment, 91, 490-507.

Fernandes, R. A., Miller, J. R., Chen, J. M., \& Rubinstein, I. G. (2004). Evaluating image-based estimates of leaf area index in boreal conifer stands over a range of scales using high-resolution CASI imagery. Remote Sensing of Environment, 89, 200-216.

Grier, C. G., \& Running, S. W. (1977). Leaf area of mature northwestern coniferous forests: Relation to site water balance. Ecology, 58, 893-899.

Hansen, M., DeFries, R. S., Townshend, J. R. G., Carroll, M., Dimiceli, C., \& Sohlberg, R. A (2003). Global percent tree cover at a spatial resolution of 500 meters: First results of the MODIS vegetation continuous fields algorithm. Earth Interactions, 7(10), $1-15$

Heinsch, F. A., Zhao, M., Running, S., Kimball, J. S., Nemani, R., Davis, A. B., Bolstad, P. V., Cook, B. D., Desai, A. R., Ricciuto, D. M., Law, B. E., Oechel, W. C., Kwon, H., Luo, H., Wofsy, S. C., Dunn, A. L., Munger, J. W., Baldocchi, D. D., Xu, L., Hollinger, D. Y., Richardson, A. D., Stoy, P. C., Siqueira, M. B. S., Monson, R. K., Burns, S. P., \& Lawrence, B. F. (2006). Evaluation of remote sensing based terrestrial productivity from MODIS using regional tower eddy flux network observations. IEEE Transactions on Geoscience and Remote Sensing, 44, 1908-1925.

Hill, M. J., Senarath, U., Lee, A., Zeppel, M., Nightingale, J. M., Williams, R. D. J., \& McVicar, T. R. (2006). Assessment of the MODIS LAI product for Australian ecosystems. Remote Sensing of Environment, 101, 495-518.

Hirata, Y., Sato, K., Sakai, A., Kuramoto, S., \& Akiyama, Y. (2003). The extraction of canopy-understory vegetation-topography structure using helicopter-borne LIDAR measurement between a plantation and a broad-leaved forest. Geoscience and Remote Sensing Symposium, 2003. IGARSS '03. Proceedings. 2003 IEEE International Geoscience and Remote Sensing Symposium, 2003. IGARSS '03. Proceedings. 2003 IEEE International VO - 5, Vol. 3225. (pp. 3222-3224).

Huang, D., Knyazikhin, Y., Wang, W., Deering, D. W., Stenberg, P., Shabanov, N., Tan, B., \& Myneni, R. B. (2008). Stochastic transport theory for investigating the three-dimensional canopy structure from space measurements. Remote Sensing of Environment, 112, 35-50.

Huang, D., Yang, W., Tan, B., Rautianinen, M., Zhang, P., Hu, J., Shabanov, N. V., Linder, S., Knyazikhin, Y., \& Myneni, R. B. (2006). The importance of measurement errors for deriving accurate reference leaf area index maps for validation of moderateresolution satellite LAI products. IEEE Transactions on Geoscience and Remote Sensing, 44, 1866-1871.

Hudak, A. T., Crookston, N. L., Evans, J. S., Falkowski, M. J., Smith, A. M. S., Gessler, P. E., \& Morgan, P. (2006). Regression modeling and mapping of coniferous forest basal area and tree density from discrete-return lidar and multispectral satellite data. Canadian Journal of Remote Sensing, 32, 126-138.

Jensen, J. L. R., Humes, K. S., Vierling, L. A., \& Hudak, A. T. (2008). Discrete return lidar-based prediction of leaf area index in two conifer forests. Remote Sensing of Environment, 112, 3947-3957.

Jin, Z., Tian, Q., Chen, J. M., \& Chen, M. (2007). Spatial scaling between leaf area index maps of different resolutions. Journal of Environmental Management, 85, 628-637.

Jordan, C. F. (1969). Derivation of leaf area index from quality of light on the forest floor. Ecology, 50, 663-666.

Knyazikhin, Y., Glassy, J., Privette, J. L., Tian, Y., Lotsch, A., Zhang, Y., Wang, Y., Morisette, J. T., Votava, P., Myneni, R. B., Nemani, R. R., \& Running, S. W. (1999). MODIS leaf area index (LAI) and fraction of photosynthetically active radiation absorbed by vegetation (FPAR) product (MOD15) algorithm theoretical basis document. http://modis.gsfc.nasa.gov/data/atbd/atbd_mod15.pdf

Knyazikhin, Y., Martonchik, J. V., Myneni, R. B., Diner, D. J., \& Running, S. W. (1998). Synergistic algorithm for estimating vegetation canopy leaf area index and fraction of phytosynthetically active radiation from MODIS and MISR data. Journal of Geophysical Research, 103, 32239-32356.

Law, B. E., Van Tuyl, S., Cescatti, A., \& Baldocchi, D. D. (2001). Estimation of leaf area index in open-canopy ponderosa pine forests at different successional stages and management regimes in Oregon. Agricultural and Forest Meteorology, 108, 1-14.

Lefsky, M. A. (2010). A global forest canopy height map from the Moderate Resolution Imaging Spectroradiometer and the Geoscience Laser Altimeter System. Geophysical Research Letters, 37, L15401 5 pp.

Martinuzzi, S., Vierling, L. A., Gould, W. A., Falkowski, M. J., Evans, J. S., Hudak, A. T., \& Vierling, K. T. (2009). Mapping snags and understory shrubs for a LiDAR-based assessment of wildlife habitat suitability. Remote Sensing of Environment, 113, 2533-2546.

Morisette, J. T., Baret, F., Privette, J. L., Myneni, R. B., Nickeson, J. E., Garrigues, S., Shabanov, N. V., Weiss, M., Fernandes, R. A., Leblanc, S. G., Kalacska, M., Sanchex-Azofeifa, G. A. Chubey, M., Rivard, B., Stenberg, P., Rautianinen, M., Voipio, P., Manninen, T., Pilant, A. N., Lewis, T. E., Iiames, J. S., Colombo, R., Meroni, M., Busetto, L., Cohen, W. B., Turner, D. P., Warner, E. D., Peterson, G. W., Seufert, G., \& Cook, R. (2006). Validation of global moderate-resolution LAI products: A framework proposed within the CEOS land product validation subgroup. IEEE Transactions on Geoscience and Remote Sensing, 44, 1804-1817. 
Morsdorf, F., Kotz, B., Meier, E., Itten, K. I., \& Allgower, B. (2006). Estimation of LAI and fractional cover from small footprint airborne laser scanning data based on gap fraction. Remote Sensing of Environment, 104, 50-61.

Myneni, R. B., Hoffman, S., Knyazikhin, Y., Privette, J. L., Glassy, J., Tian, Y., Wang, Y., Song, X. Zhang. Y., Smith, G. R., Lotsch, A., Friedl, M., Morisette, J. T., Votava, P., Nemani, R. R., \& Running, S. W. (2002). Global products of vegetation leaf area and fraction absorbed PAR from year one of MODIS data. Remote Sensing of Environment, 83, 214-231.

Myneni, R. B., Nemani, R. R., \& Running, S. W. (1997). Estimation of global leaf area index and absorbed par using radiative transfer models. IEEE Transactions on Geoscience and Remote Sensing, 35, 1380-1393.

Neter, J., Wasserman, W., \& Kutner, M. H. (1985). Applied linear statistical models. Homewood, IL: Irwin.

Nishihama, M., Wolfe, R., Solomon, D., Patt, F., Blanchette, J., Fleig, A., \& Masuoka, E. (1997). MODIS level 1A Earth location: Algorithm theoretical basis document. Version

Oker-Blom, P., \& Smolander, H. (1988). The ratio of shoot silhouette area to total needle area in Scots pine. Forest Science, 34, 894-906.

Pisek, J., \& Chen, J. M. (2007). Comparison and validation of MODIS and VEGETATION global LAI products over four BigFoot sites in North America. Remote Sensing of Environment, 109, 81-94.

Pocewicz, A. L., Gessler, P., \& Robinson, A. P. (2004). The relationship between effective plant area index and Landsat spectral response across elevation, solar insolation, and spatial scales in a northern Idaho forest. Canadian Journal of Forest Research, 34, 465-480.

Rautiainen, M. (2005). Retrieval of leaf area index for a coniferous forest by inverting a forest reflectance model. Remote Sensing of Environment, 99, 295-303.

Riaño, D., Valladares, F., Condes, S., \& Chuvieco, E. (2004). Estimation of leaf area index and covered ground from airborne laser scanner (Lidar) in two contrasting forests. Agricultural and Forest Meteorology, 124, 269-275.

Running, S. W., \& Coughlan, J. C. (1988). A general model of forest ecosystem processes for regional applications I. Hydrologic balance, canopy gas exchange and primary production processes. Ecological Modeling, 42, 125-154.

Sappington, J. M., Longshore, K. M., \& Thompson, D. B. (2005). Quantifying landscape ruggedness for animal habitat analysis: A case study using bighorn sheep in the Mojave Desert. The Journal of Wildlife Management, 71, 1419-1426.

Sellers, P. J., Randall, D. A., Betts, A. K., Hall, F. G., Berry, J. A., Collatz, G. J., Denning, A. S, Mooney, H. A., Nobre, C. A., Sato, N., Field, C. B., \& Henderson-sellers, A. (1997) Modeling the exchanges of energy, water, and carbon between continents and the atmosphere. Science, 275, 502-509.

Smith, N. J., Chen, J. M., \& Black, T. A. (1993). Effects of clumping on estimates of stand leaf area using the LI-COR LAI-2000. Canadian Journal of Forest Research, 23, 1940-1943.

Steinberg. D. C., \& Goetz, S. (2009). Assessment and extension of the MODIS FPAR products in temperate forests of the eastern United States. International Journal of Remote Sensing, 30, 169-187.

Steinberg, D. C., Goetz, S., \& Hyer, E. J. (2006). Validation of MODIS FPAR products in boreal forests of Alaska. IEEE Transactions on Geoscience and Remote Sensing, 44(7), 1818-1828.

Suguira, N. (1978). Further analysis of the data by Akaike's information crierion and the finite corrections. Communication in Statistics, A, 7, 13-26.

Tan, B., Hu, J., Huang, D., Yang, W., Zhang, P., Shabanov, N. V., Knyazikhin, Y., Nemani, R. R., \& Myneni, R. B. (2005). Assessment of the broadleaf crops leaf area index product from the Terra MODIS instrument. Agricultural and Forest Meteorology, 135, 124-134.
Tian, Y., Dickinson, R. E., Zhou, L., Zeng, X., Dai, Y., Myneni, R. B., Knyazikhin, Y., Zhang, X., Friedl, M., Yu, H., Wu, W., \& Shaikh, M. (2004). Comparison of seasonal and spatial variations of leaf area index and fraction of absorbed photosynthetically active radiation from Moderate Resolution Imaging Spectroradiometer (MODIS) and Common Land Model as they relate to the validation of MOD15. Journal of Geophysical Research, Atmosphere, 109(D01), 103.

Tian, Y., Woodcock, C. E., Wang, Y., Privette, J. L., Shabanov, N. V., Zhou, L., Zhang, Y., Buermann, W., Dong, J., Veikkanen, B., Häme, T., Andersson, K., Ozdogan, M., Knyazikhin, Y., \& Myneni, R. B. (2002). Multiscale analysis and validation of the MODIS LAI product: I. Uncertainty assessment. Remote Sensing of Environment, 83, 414-430.

Turner, D. P., Cohen, W. B., Kennedy, R. E., Fassnacht, K. S., \& Briggs, J. M. (1999). Relationships between leaf area index and Landsat spectral vegetation indices across three temperate zone sites. Remote Sensing of Environment, 70, 52-68.

Turner, D. P., Ollinger, S. V., \& Kimball, J. S. (2004). Integrating remote sensing and ecosystem process models for landscape- to regional-scale analysis of the carbon cycle. BioScience, 54, 573-584.

Wang, Y., Tian, Y., Zhang, Y., El-Saleous, N., Knyazikhin, Y., Vermote, E., \& Myneni, R. B. (2001). Investigation of product accuracy as a function of input and model uncertainties: Case study with SeaWiFS and MODIS LAI/FPAR algorithm. Remote Sensing of Environment, 78, 299-313.

Wang Y. Woodcock, C. E., Buermann, W. Stenberg P. Voipio, P. Smolander, H., Hame, T., Tian, Y., Hu, J., Knyazikhin, Y., \& Myneni, R. B. (2004). Evaluation of the MODIS LAI algorithm at a coniferous forest site in Finland. Remote Sensing of Environment, 91, 114-127.

Welles, J. M., \& Norman, J. M. (1991). Instrument for indirect measurement of canopy architecture. Agronomy Journal, 83, 818-825.

White, J. D., Running, S. W., Nemani, R., Keane, R. E., \& Ryan, K. C. (1997). Measurement and remote sensing of LAI in Rocky Mountain montane ecosystems. Canadian Journal of Forest Research, 27, 1714-1727.

Wolfe, R. E., Nishihama, M., Fleig, A. J., Kuyper, J. A., Roy, D. P., Storey, J. C., \& Patt, F. S. (2002). Achieving sub-pixel geolocation accuracy in support of MODIS land science. Remote Sensing of Environment, 83, 31-49.

Yang, W., Huang, D., Tan, B., Stroeve, J. C., Shabanov, N. V., Knyazikhin, Y., Nemani, R. R., \& Myneni, R. B. (2006). Analysis of leaf area index and fraction of PAR absorbed by vegetation products from the Terra MODIS sensor: 2000-2005. IEEE Transactions on Geoscience and Remote Sensing, 44, 1829-1842.

Yang, W., Shabanov, N. V., Huang, D., Wang, W., Dickinson, R. E., Nemani, R. R., Knyazikhin, Y., \& Myneni, R. B. (2006). Analysis of leaf area index products from combination of MODIS Terra and Aqua data. Remote Sensing of Environment, 104, 297-312.

Yang, W., Tan, B., Huang, D., Rautiainen, M., Shabanov, N. V., Wang, Y., Privette, J. L., Huemmrich, K. F., Fensholt, R., Sandholt, I., Weiss, M., Ahl, D. E., Gower, S. T., Nemani, R. R., Knyazikhin, Y., \& Myneni, R. B. (2006). MODIS leaf area index products: From validation to algorithm improvement. IEEE Transactions on Geoscience and Remote Sensing, 44, 1885-1898.

Yi, Y., Yang, D., Huang, J., \& Chen, D. (2008). Evaluation of MODIS surface reflectance products for wheat leaf area index (LAI) retrieval. ISPRS Journal of Photogrammetry and Remote Sensing, 63, 661-677.

Zhao, K., \& Popescu, S. (2009). Lidar-based mapping of leaf area index and its use for validating GLOBCARBON satellite LAI product in a temperate forest of the southern USA. Remote Sensing of Environment, 113, 1628-1645. 